NBER WORKING PAPER SERIES

\title{
SOCIOECONOMIC STATUS AND HEALTH: DIMENSIONS AND MECHANISMS
}

\author{
David M. Cutler \\ Adriana Lleras-Muney \\ Tom Vogl \\ Working Paper 14333 \\ http://www.nber.org/papers/w14333
}
NATIONAL BUREAU OF ECONOMIC RESEARCH
1050 Massachusetts Avenue
Cambridge, MA 02138
September 2008

We thank Sherry Glied and Peter Smith for comments. This research has been supported by the National Science Foundation GRFP and the National Institutes on Aging. The views expressed herein are those of the author(s) and do not necessarily reflect the views of the National Bureau of Economic Research.

NBER working papers are circulated for discussion and comment purposes. They have not been peerreviewed or been subject to the review by the NBER Board of Directors that accompanies official NBER publications.

(C) 2008 by David M. Cutler, Adriana Lleras-Muney, and Tom Vogl. All rights reserved. Short sections of text, not to exceed two paragraphs, may be quoted without explicit permission provided that full credit, including $\odot$ notice, is given to the source. 
Socioeconomic Status and Health: Dimensions and Mechanisms

David M. Cutler, Adriana Lleras-Muney, and Tom Vogl

NBER Working Paper No. 14333

September 2008

JEL No. I1

\begin{abstract} socioeconomic status as a unified concept.

David M. Cutler

Department of Economics

Harvard University

1875 Cambridge Street

Cambridge, MA 02138

and NBER

dcutler@harvard.edu

Adriana Lleras-Muney

Department of Economics

UCLA

9373 Bunche Hall

Los Angeles CA 90095-1477

and NBER

alleras@ECON.UCLA.EDU

Tom Vogl

Harvard University

tvogl@fas.harvard.edu
\end{abstract}

This paper reviews the evidence on the well-known positive association between socioeconomic status and health. We focus on four dimensions of socioeconomic status -- education, financial resources, rank, and race and ethnicity -- paying particular attention to how the mechanisms linking health to each of these dimensions diverge and coincide. The extent to which socioeconomic advantage causes good health varies, both across these four dimensions and across the phases of the lifecycle. Circumstances in early life play a crucial role in determining the co-evolution of socioeconomic status and health throughout adulthood. In adulthood, a considerable part of the association runs from health to socioeconomic status, at least in the case of wealth. The diversity of pathways casts doubt upon theories that treat 


\section{Introduction}

In societies rich and poor, those of greater privilege tend to enjoy better health. Among older adults in Britain and the United States, a move from the top education or income tercile to the bottom tercile is associated with an increase of at least fifteen percentage points in the likelihood of reporting fair or poor health (Banks et al. forthcoming). The Mexican elderly share this pattern, with the poorest and least educated terciles reporting poor health at least ten percentage points more often than the richest and most educated terciles (Smith and Goldman 2007). Mortality differences are just as striking. For the United States and six European countries, Figure 1 shows the increase in mortality risk associated with having less than uppersecondary education (according to the International Standard Classification of Education). Compared with their better educated compatriots, those with less than upper-secondary education are at least 20 percent more likely to die in a given year. Figure 1 reveals some variation across countries, but this variation appears to have little to do with differences in health care systems. For example, the mortality differentials for the United States, which favors market-based health care (at least for the non-elderly), and Austria, where the government provides universal health care, are virtually identical.

The scientific study of this relationship (commonly referred to as the 'gradient') between socioeconomic status (SES) and health dates back at least as far as the $19^{\text {th }}$ century, when researchers investigated differences in health outcomes among royalty, the landed elite, and the working class in Europe. ${ }^{1}$ Since then, measures of SES have come to appear regularly in

\footnotetext{
${ }^{1}$ See Antonovsky (1967) for a review of the pre-1960 literature on the SES-health gradient. This literature documents a positive correlation between SES and health holding environmental conditions constant. However, during historical eras of urbanization, the tendency of the wealthy to locate in urban areas increased their exposure to unsanitary conditions, obfuscating the gradient in analyses that pooled individuals living in urban and rural areas (Mosk and Johansson 1986; Haines 2001). Similarly, members of British ducal families did not enjoy a mortality advantage over the common population until about 1750, perhaps because of the dispersal of the common population across sparsely populated rural areas (Harris 2004).
} 
analyses of the determinants of health and mortality. Given that a variety of socioeconomic variables — including income, education, occupation, race, and ethnicity, among others — exhibit similar associations with health, many researchers have come to agree that "a broader underlying dimension of social stratification or social ordering is the potent factor" (Adler et al. 1994, p. 15), so that the various SES variables primarily serve as indicators, or 'markers,' of this underlying dimension. $^{2}$ This view emphasizes the broad influence of SES, rather than the effects of specific resources and hierarchies.

However, recent evidence suggests that treating SES as a unified concept is not correct. SES consists of not one but many dimensions, which relate to health in diverse ways. Different measures of SES may operate through different mechanisms, and it is useful to explore these mechanisms precisely. For example, short term positive fluctuations in income appear to reduce health, whereas long term measures of income and wealth are positively correlated with better health. Education tends to remain stable throughout adulthood so these patterns would not be observed if one used education as a measure of SES.

For those interested in designing policies to address the gradient, an understanding of this diversity of mechanisms is indispensable. Some dimensions of socioeconomic status may be more susceptible to manipulation than others - income transfers, for example, are more easily designed than policies that affect occupational choices. The multiplicity of mechanisms also raises questions about cost effectiveness. If policy-makers wish to improve health, are public funds better spent on income transfers, education, or public health programs? Furthermore, if for some dimensions of SES the gradient runs primarily from health to SES, then policy manipulations of these dimensions will have no impact on health. In fact, in these cases, policies that improve health may, as a side effect, boost access to certain resources. Policy efforts to

\footnotetext{
${ }^{2}$ See also Link and Phelan (1995) on SES as a "fundamental" (and unidimensional) cause of disease.
} 
affect health through SES will similarly be fruitless when the SES-health correlation reflects an underlying 'third factor' that we do not observe.

In this chapter, we review the past two decades of research on the SES-health gradient, paying particular attention to how the mechanisms linking health to each of the dimensions of SES diverge and coincide. We divide the concept of SES into four domains-education, financial resources, rank, and race and ethnicity_arguing that each of these deserves attention in its own right. After laying out some basic facts about the SES-health gradient (Section II), we devote a separate section to each of these socioeconomic correlates of health. In Sections III and IV, which treat education and financial resources, we concentrate on conceptual approaches that view the individual in isolation, as is commonplace in economics (Grossman 1972). The section on rank (Section $\mathrm{V}$ ) is situated in a more sociological setting, paying attention to the interplay between the individual and society. The links between occupation and health are the focus of this section, but we also revisit the gradients in education and financial resources, now viewing them through the lens of social rank. Section VI then summarizes the evidence on racial and ethnic differences in health, and in Section VII we provide some concluding remarks.

Two themes surface repeatedly in the discussion. Throughout, we emphasize that the extent to which socioeconomic advantage causes good health varies, both across these four dimensions and across the phases of the lifecycle. Circumstances in early life play a crucial role in determining the co-evolution of socioeconomic status and health throughout adulthood. We also periodically comment on the interdisciplinary nature of research on the SES-health gradient. The literature we review features contributions from economics, sociology, demography, epidemiology, psychology, and evolutionary biology, among others. We take note of what economists have learned from other disciplines and how the concepts and methods of economics 
have advanced the state of knowledge on socioeconomic status and health. In the last two decades, economists' most substantial contributions to this literature have involved untangling causal mechanisms.

Although the SES-health gradient is observed in societies at all phases of economic development, in order to contain the discussion, we focus on the evidence pertaining to the contemporary industrialized world. When appropriate, we touch upon the evidence from poorer countries, commenting on how it squares with the evidence from their wealthier counterparts. Still, a detailed discussion of the gradient in developing settings is beyond the scope of this chapter. However, given the harshness of the binding economic constraints in such settings, the SES-health gradient and its underlying mechanisms demand further attention in poor countries. ${ }^{3}$

To conclude each section, we remark on the lingering puzzles. Whatever gains the literature has made since the appeals of the late 1980s and early 1990s, much remains to be learned. This chapter is as much an overview of the current knowledge as it is a call for future research.

\section{Socioeconomic Status and Health: Some Facts}

In this section, we motivate the discussion by describing the relationship between SES and health in the United States, an institutional setting with which we are familiar. Given the similar mortality-education relationships across countries in Figure 1, an in-depth look at a single country may also illuminate the gradients in other countries. Moreover, the methods we use here are easily applied to data from other settings.

\footnotetext{
${ }^{3}$ For an overview of the socioeconomic determinants of health in developing countries, see Strauss and Thomas (1998).
} 
We use data from the National Health Interview Surveys of 1986 through 1995, and we consider two commonly used measures of health: mortality, an objective but blunt measure of health, and self-reported health status (SRHS), which captures quality of life and has been shown to be highly correlated with objective measures of health, including mortality (Idler and Benyamini 1997). SRHS can take 5 values; a value of 1 corresponds to excellent health and 5 to poor health. We restrict our attention to these waves of the NHIS because more recent 5-year mortality follow-up data are not available.

We start by plotting the relationship between education and 5-year mortality for 10-year age groups. Figure 2a shows that those with more then 16 years of school have substantially lower mortality rates than those with less than 8 years of school, and the relationship is more or less monotonic in between. To interpret the age patterns in the figure, one must first decide whether to concentrate on absolute or relative differences in mortality risk. In absolute terms, the gradient steepens as individuals age. However, because the elderly have high mortality rates at all levels of education, the relative effect of education is weakest among individuals ages 65 and over. As shown in Figure 2b, more education is also associated with better self reported health. Among all age groups, each additional year of schooling is associated with a clear and consistent improvement in SRHS. As in the case of relative mortality risk, the effect of education is smallest among those aged 65 and over.

In Figures $3 a$ and $3 b$, we repeat the exercise using household income instead of education. For mortality (Figure 3a), we use local logistic regression, a semi-parametric method that allows for flexible estimation of relationships with binary dependent variables (Fan et al. 1998). We see that income is protective for all age groups, with the association strongest at lower levels of household income. Figure $3 \mathrm{~b}$ then applies local linear regression, a non- 
parametric smoother similar to the method used in Figure 2a (Fan 1992), to estimate the relationship between income and SRHS. Income is also associated with better self-reported health. We note a clear pattern in the SRHS results, first documented by Case et al (2002): the profile becomes steeper with age until age 64 and then flattens among the elderly. The income gradient among children, whose health status is reported by parents, also steepens with age (results not shown). Already these results suggest that the effect of income and that of education may be independent: for most age groups, the effect of education on either outcome does not appear to decrease at high levels of education, whereas the effect of income does. ${ }^{4}$

To document the health gradient in rank, our third dimension of SES, Figure 4 shows occupational patterns of mortality among working age adults. The populations within age groups are standardized to the age and sex structure of the United States in the 2000 census, so that they are directly comparable across occupation categories. The categories are ordered to reflect decreasing "rank." They include (1) managerial, professional, and executive occupations; (2) technical, sales, and administrative occupations; (3) service occupations, which consist of protective services, household services, and precision production, among others; and (4) manual labor, which includes machine operators, fabricators, and various other laborers. While the groupings are obviously arbitrary (they are the NHIS's, not ours), mortality rates appear to rise with each incremental decrease in occupational rank.

Figures $5 \mathrm{a}$ and $5 \mathrm{~b}$ then look at differences in mortality and SRHS by ethnicity and race. We split the sample into three categories: non-Hispanic whites, non-Hispanic blacks, and

\footnotetext{
${ }^{4}$ Formally, this fact does not rule out the possibility that education and income work through the same channel. In particular, the earnings-schooling relationship has become convex (Mincer 1997; Deschênes 2001; Lemieux 2006). If education and income affect health through the same channel, then the combination of a convex income-schooling profile and a concave health-income profile admits any shape for the health-education profile, as long as health is increasing in education. Nonetheless, the sharp differences between Figures 1 and 2 are give reason to doubt that education and income affect health in an identical way.
} 
Hispanics. At every age, blacks experience higher mortality than whites or Hispanics, and the gap widens as people age. Hispanics exhibit a very different pattern, with higher mortality than whites at younger ages but lower mortality after roughly age 50 . Since our sample is not restricted to the native born, changes in the composition of migrants over time could explain the age pattern. Nevertheless, the health advantage of this otherwise relatively disadvantaged population, at least among some age groups, is interesting. Surprisingly, SRHS does not show the same pattern. Across all ages, blacks report themselves to be in worse health than Hispanics, and Hispanics report worse health than whites. ${ }^{5}$ Black-white differences remain largest among older individuals.

Overall, these figures suggest differences across SES measures; each measure may relate to health through a different set of mechanisms. We explore this further in Table 1, which uses data from the 1990 NHIS to estimate the relationships described in Figures 1-4, now with a focus on working-age adults. We limit the analysis to the 1990 wave of the survey in order to take advantage of the rich set of covariates available for that sample. In the left-hand panel, we estimate the relationship between 10-year mortality and each SES measure using logistic regression; in the right-hand panel, we repeat this exercise for self-reported fair or poor health. We report marginal effects estimated at the means of all independent variables. We multiply all estimates by 100 in order to express the marginal effects in percentage point units.

In the first column, we report the marginal effects from models that include each SES variable by itself in addition to basic demographic controls (age, gender, region and size of metropolitan area, marital status and family size). The results reproduce the results in Figures 14 and those commonly found in the literature. Education (measured in years) is associated with

\footnotetext{
${ }^{5}$ Bzostek et al. (2007) assess the reasons for this contradictory evidence on ethnic differences in mortality and SRHS. They argue that language barriers, educational differences, and the somatization of emotional distress by Hispanics explain some of the divergence, but much remains to be learned on this issue.
} 
lower mortality, as is higher income. Workers in lower status occupations face significantly higher mortality rates than their higher status counterparts. Workers in all four categories enjoy better survival rates than individuals not in the labor force. Finally, we find that African Americans have higher mortality than whites. Hispanics, too, are more likely to die than nonHispanic whites in this sample, but the difference in mortality risk is considerably smaller than the black-white difference.

Column (2) reports results from a model that include all SES measures together. Comparing columns (1) and (2), several conclusions emerge. The associations of education and income with mortality fall in magnitude but remain significant. In other words, an extra year of schooling reduces mortality among those with identical income, occupation, race and ethnicity. Similarly, an increase in household income is associated with lower mortality even controlling for other SES characteristics. However, occupational status is no longer significantly related to the probability of dying, except that those out of the labor force have higher mortality rates than those that are employed. ${ }^{6}$ Furthermore, while blacks still face significantly higher mortality rates than whites, Hispanic mortality is statistically indistinguishable from white mortality.

Columns (3)-(5) consider several popular explanations for these associations. ${ }^{7}$ The first possibility we explore involves lower-SES individuals leading unhealthier lives. Column (3) reruns the model that includes all SES measures, now controlling for an array of behavioral variables, including smoking, alcohol use, physical fitness, and seat-belt use. Adjustment for health behaviors flattens the gradients in education and income, though these gradients are still

\footnotetext{
${ }^{6}$ For the specifications in columns (2)-(5), F-tests of joint significance fail to reject the hypothesis that all occupation coefficients (excluding the coefficient on labor force participation) equal zero.

${ }^{7}$ The notes to Table 1 describe the variables used for this exercise in more detail than the ensuing paragraphs. We do not address the access to health insurance as a potential explanation for the gradient because the 1990 NHIS does not include questions on health insurance coverage. However, in results from the 2000 NHIS (not shown), controlling for health insurance access reduces estimates of the SRHS gradient only negligibly. Since we do not observe long enough mortality follow-up for this sample, we focus on the 1990 NHIS here.
} 
present. Strikingly, the racial gap in mortality is larger after holding health behaviors constant. Columns (4) and (5) then consider instead whether health knowledge (measured with a series of questions about tobacco, alcohol, and heart disease) or stress (self-reported incidence over the past week or year) explain the gradient. These are rough proxies of hard-to-measure concepts, but at any rate, they fail to account for any of the observed SES differences in health.

Columns (6)-(10) present the same set of models using SRHS instead of mortality, and the results lead to similar conclusions. Education and income exhibit strong, significant gradients, in part explained by behaviors and (to a lesser extent) stress. Blacks report themselves in worse health then whites, and Hispanics are statistically indistinguishable from whites once other SES measures are added. In the case of occupations, we now find that relative to professional occupations, individuals in all other occupations report themselves in worse health; with the exception of one category, this holds true when controlling for income, education and race. The addition of health behavior covariates substantially diminishes differences by occupation, but knowledge and stress do not.

Our quick look at the NHIS suggests three facts that are important for the subsequent discussion. First, gradients exist for all measures of SES and health, with the measures of SES somewhat but not totally related. Income, education, occupation, and race are all correlated, and the common component explains a good part of the SES gradient in health. But each variable acts on its own as well. Second, the gradients vary across age groups, with many gradients initially steepening as people age and then flattening at age 65 . Whether this is due to differential impact of resources at older ages or differential mortality by SES is not entirely clear. Finally, the impact of SES is partly behavioral. At least one reason that higher SES people enjoy better health is that they are less likely to smoke, drink heavily, or be obese-although it is not 
clear why this is the case (Cutler and Lleras-Muney 2007b). Our results leave open the issue of exactly how much of the SES gradient is attributable to these individual factors.

\section{Education}

A proper starting point for any discussion of the SES-health gradient is education. In their pioneering work on the socioeconomic determinants of mortality in the United States, Kitagawa and Hauser (1973) used educational attainment as their primary indicator of SES, and since then, education has played a central role in analyses of the SES-health gradient. The focus on education has two rationales: education can be obtained for both working and non-working individuals, and education is more plausibly exogenous than income and occupation to the production of adult health (Elo and Preston 1996). Adult health may have direct morbidity effects on labor market performance, whereas any simultaneity in the education-health gradient would have to operate indirectly.

Of course, the case for reverse causality in the education-health gradient is also plausible. If good health allows children to attain more schooling and also makes them more likely to become healthy adults, then the relationship between education and adult health will in part reflect the effect of health on education (see, e.g., Case et al. 2005). Similarly, if the expectation of a longer, healthier life induces increased investment in human capital, as standard economic models of human capital accumulation predict, then the education-health gradient may be a sign of health affecting education. Nonetheless, the earlier literature deemed hypotheses of this sort less likely than those involving the direct impact of health on labor market outcomes. 
Although they are difficult to interpret, non-experimental estimates of the relationship between education and health measures abound. ${ }^{8}$ As shown in Section II, more educated individuals in the United States report better health and face lower mortality risk. They also suffer less anxiety and depression, endure fewer functional limitations, and face decreased probabilities of being diagnosed with heart conditions, stroke, hypertension, high cholesterol, emphysema, diabetes, asthma, or ulcer — even after conditioning on background characteristics such as race, age, and income. ${ }^{9}$ These differences by education also hold in a wide range of European countries (see Mackenbach 2006 and references therein).

In contrast to research on the other dimensions of SES, where evidence on causality is sparser and less consistent, analyses of natural experiments have produced evidence that schooling causes better health. ${ }^{10}$ To our knowledge, these analyses derive exclusively from the economics literature. Lleras-Muney (2005) examines U.S. cohorts affected by compulsory schooling laws in the early $20^{\text {th }}$ century, finding that individuals born in states that forced them to remain in school longer enjoyed significantly higher survival rates in adulthood. ${ }^{11}$ Analyses of the effects of compulsory schooling legislation in Europe suggest similar conclusions. ${ }^{12}$ Other evidence from the United States uses local economic conditions during the teenage years and military draft avoidance to instrument for educational attainment. Arkes (2004) takes advantage of the fact that high unemployment rates lower the opportunity cost of staying in school, finding

\footnotetext{
${ }^{8}$ The results reported in this paragraph derive from Cutler and Lleras-Muney (2007a).

${ }^{9}$ Interestingly, Cutler and Lleras-Muney (2007a) find positive education gradients for being diagnosed with cancer, small pox, or hay fever. However, their dataset is based on self reports, and they note that reporting of hay fever and certain types of cancer may reflect differential disease knowledge. For cancer, they also point out that the bettereducated have a greater tendency to display risk factors such as late childbearing, that they may be more likely to survive the disease, and that they may face lower competing risks, allowing them to live long enough to be diagnosed with cancer.

${ }^{10}$ Grossman (forthcoming) describes these studies in detail.

${ }^{11}$ Mazumder (2007) shows that the inclusion of state-specific trends across cohorts renders Lleras-Muney's mortality result statistically insignificant, although the coefficients remain large and negative. Mazumder's estimate of the effect of education on self-reported health status is robust to the inclusion of these trends.

${ }^{12}$ See Oreopolous (2007) on England and Ireland; Arendt (2005) on Denmark; and Spasojevic (2004) on Sweden.
} 
that individuals exposed to higher unemployment rates as teenagers attain higher levels of education and are less likely to suffer from conditions that limit work or require personal care. De Walque (2004) and Grimard and Parent (2007) use the effect of draft avoidance behavior on college enrollment during the Vietnam War to identify the impact of education on smoking behavior. Both studies show that education decreases the probability that an individual currently smokes or ever smoked. ${ }^{13}$

The health benefits of education also flow intergenerationally. Better-educated parentsand especially mothers_-have healthier children (Meara 2001; Currie and Moretti 2003), and these children grow up to be healthier adults (Case et al. 2005) ${ }^{14}$ Currie and Moretti (2003) use college openings in mothers' localities to identify plausibly exogenous variation in maternal college going, finding positive effects on birthweight and negative effects on smoking during pregnancy. Unlike the effects of parental income, described in the next section, the effects of parental education on child health do not appear to vary systematically with the child's age (Case et al. 2002).

In their review of the literature on the education-health gradient, Cutler and LlerasMuney (2007a) point out several shortcomings of these quasi-experimental studies. First, the studies concentrate solely on the quantity of education, providing no insight into how its quality or content affect health. Nor do they shed a great deal of light on the mechanisms mediating the causal relationship. Finally, as in any instrumental variables setting, the estimates correspond to local average treatment effects; they identify the effect of schooling among individuals on the margin of dropping out of high school (in the case of compulsory schooling laws and local

\footnotetext{
${ }^{13}$ However, De Walque (2004) and Grimard and Parent (2007) find mixed results for smoking cessation (among individuals who started smoking in high school).

${ }^{14}$ The literature on developing countries has long observed that maternal education is positively related to child health, starting with Caldwell (1979). Recent estimates based on increases in educational attainment following a massive school construction project in Pakistan confirm that this relationship is causal (Breirova and Duflo 2004).
} 
unemployment rates) or on the margin of attending college (in the case of draft avoidance). ${ }^{15}$

The average effect of education on health among these individuals may differ substantially from the average effect across the population. As such, the magnitudes of the quasi-experimental estimates may lack external validity.

Although these studies support the hypothesis that that education improves health, another body of evidence indicates that health also affects education. Again, methodological advances in economics have played a key role in identifying this direction of causation. The evidence on contemporary industrialized countries derives primarily from non-experimental but data-rich longitudinal studies on both individuals and twins. In Britain, adolescents who were born with low birthweight or suffered health insults in childhood have worse schooling outcomes (Case et al. 2005). Among twin pairs in the United States and Norway, those born with lower birthweight than their twins stay in school commensurately fewer years (Behrman and Rosenzweig 2004; Black et al. 2007). Further confirmation is available from natural experiments in the histories of industrialized countries. Almond (2006), studying the long-run effects of the 1918 influenza epidemic in the United States, shows that cohorts exposed to the epidemic in utero arrived at adulthood with lower educational attainment. Similarly, Bleakley (2007) examines the impact of hookworm eradication in the American South, finding significant effects on education and literacy.

Not surprisingly, these results are consistent with evidence from many developing countries, where the constraining effects of poor childhood health are likely to be stronger than in industrialized countries. Miguel and Kremer (2004) present the results of a randomized, controlled trial that administered deworming pills to school-age children in Kenya. They

\footnotetext{
${ }^{15}$ For a discussion of this issue as it pertains to the economic returns to schooling, see Card (2001). Also see Imbens and Angrist (1994) for an introduction to the concept of the local average treatment effect.
} 
confirm Bleakley's long-run results, showing a sizeable, positive impact on school attendance. Bobonis et al. (2006), also evaluating a randomized trial, find that iron supplementation increases pre-school attendance in India. These randomized experiments also square with the quasiexperimental evidence from developing countries. Retrospective evaluations of malaria eradication campaigns in several countries indicate that these campaigns increased literacy, and sometimes schooling attainment, among individuals exposed to them in childhood (Lucas 2005; Bleakley 2007). Likewise, iodine supplementation programs have been found to boost schooling attainment among individuals exposed to them in utero (Field 2007), as would be expected in light of the importance of iodine in fetal brain development.

These studies seem to imply that health affects schooling attainment either through its effects on morbidity—with ill children unable to attend school often and unable to concentrate when they do attend —or through its effects on cognitive development. Another hypothesis, with support in recent work by Jayachandran and Lleras-Muney (forthcoming), suggests that the expectation of a longer life induces greater investment in human capital. How these mechanisms weigh against one another is an open research question.

Although little experimental or quasi-experimental evidence exists on the mechanisms linking education and health, the theories and evidence on this issue are worthy of discussion. Income mediates some of the relationship between education and health, but this is not the whole story. As shown in Section II, the protective effect of education remains even after controlling for income. Further, estimates of the effect of education on income and of the effect of income on health are too small for income to account for all of the health differences across education groups. Controlling for occupation, race, and ethnicity also fails to eliminate the education 
gradient. Thus, differences in health by education do not seem to stem only from differences in the labor market outcomes of more and less educated individuals.

The remaining health differences have significant behavioral antecedents. ${ }^{16}$ The better educated are less likely to smoke (as already noted), drink excessively, carry excess weight, or use illegal drugs. In the sense that these patterns reflect lower spending on certain goods by people with more education, they challenge income-based explanations for the gradient-these posit that the greater wealth of the better educated allows them to spend more on health. ${ }^{17}$ Those with more education also obtain more preventive care (e.g., flu shots and mammograms), manage existing conditions more effectively (e.g., diabetes and hypertension), and make more use of safety devices such as seat belts and smoke detectors. In our sample of non-elderly American adults, a subset of these differences in health behaviors account for over 40 percent of the relationship between education and mortality (Table 1$).{ }^{18}$

Even if we were able to convincingly explain away all of the effect of education on mortality using behaviors, an important question would remain: why do more educated individuals behave more healthily? An obvious explanation for these differences in behaviors is that more educated individuals are better informed. However, the results presented here (and elsewhere) show that only a small fraction of the education gradient can be attributed to information alone.

Part of the answer may lie in cognitive ability, which differs from knowledge per se. Cutler and Lleras-Muney (2007b) find suggestive evidence that education affects cognition,

\footnotetext{
${ }^{16}$ The results reported in this paragraph again draw on Cutler and Lleras-Muney (2007a).

${ }^{17}$ However, these patterns are consistent with an income-based explanation if tobacco, alcohol, excess weight, and illegal drugs are inferior goods.

${ }^{18}$ Measurement error and unobserved heterogeneity may bias the estimated share of the education-mortality association attributable to behavior. The direction of this bias is most likely towards zero, although it is theoretically ambiguous.
} 
which in turn affects the ability to process information regarding healthy behaviors. ${ }^{19}$ For example, better educated people perform better on cognitive tests, and this seems to explain some of the behavior-education gradient.

Relatedly, more educated individuals are more likely to take advantage of new medical technologies. Holding income and health insurance status fixed, more educated individuals have higher take-up of medications recently approved by the F.D.A. (Lleras-Muney and Lichtenberg 2002). The effect is driven by medications that involve long-term use by the patient, suggesting a role for learning and self-management. Accordingly, the survival benefits of education accrue disproportionately to individuals with chronic diseases (Lakdawalla and Goldman 2001; Case et al. 2005), which involve self-management and learning, as well as diseases for which treatment technologies have advanced most rapidly (Glied and Lleras-Muney 2008). These patterns of technology adoption are consistent with the mediating role of cognitive ability. More broadly, they support Link and Phelan's (1995) premise that individuals of higher education (and higher SES generally) are better equipped to recognize, understand, and access new disease knowledge and medical technologies. ${ }^{20}$

Other theories emphasize differences in preferences and differences in the ability of individuals to change their behavior. In the case of preferences, differences in how individuals discount the future or react to risk may jointly determine educational attainment and health investments. For example, less patient individuals may be less willing to stay in school to boost future earnings, as well as less willing to forego smoking to avoid future disease. Furthermore, more educated individuals may have more control over their lives, or be less depressed. Although patience, depression and a sense of control over one's live affect health behaviors,

\footnotetext{
${ }^{19}$ Cutler and Lleras-Muney (2007b) also consider the possibility that heterogeneity in discount rates and risk aversion jointly determine educational attainment and health investments, but they find no evidence that this is so. ${ }^{20}$ Cutler et al. (2006) emphasize Link and Phelan's hypothesis in their review of the determinants of mortality.
} 
Cutler and Lleras-Muney (2007b) find that these theories cannot explain behavioral differences between more and less educated individuals. A final, prominent theory emphasizes the effect of stress. We will review this theory in more detail below. At this juncture, we simply note that we did not find here or in previous work evidence that stress can account for education gradients. Nonetheless, these hypotheses are difficult to test, and the concepts that underlie them elude precise measurement.

In sum, education is strongly related to health, with some reverse causality but a major direct effect as well. However, the extent to which the correlation between education and health reflects direct causality, reverse causality, or omitted factors is not known. Although the mechanisms by which health affects educational attainment are well understood, how education affects health is not. We suspect that cognitive ability represents a significant part of the link between education and health, but other factors may also be at work. It seems unlikely that any one mechanism alone can explain the effect of education on health.

\section{Financial Resources}

Both income and wealth have strong independent correlations with health, net of education and other measures of SES. Assessing causality is difficult, however. Income and wealth improve access to health inputs (such as medical care and food), but health improves one's ability to participate in the labor market and earn a decent wage. Illness also raises health care spending, thus reducing wealth. Additionally, 'third factors' — such as education-may determine both financial resources and health status. Despite these caveats, many public health researchers have attributed the health-income gradient to a causal effect running from income to health. Some have even gone as far as labeling income "one of the most profound influences on 
mortality" (Wilkinson 1990, p. 412). Initial research seemed to support this view-in one such study, McDonough et al. (1997) estimated that a move from a household income of \$20,000$\$ 30,000$ to a household income greater than $\$ 70,000$ (in 1993 dollars) was associated with a halving of the odds of adult mortality. It was difficult to fathom that an association so large could be entirely due to omitted variables or reverse causality. However, more recent studies suggest that the direction of causality is far from clear and, furthermore, that it varies considerably by age.

Among adults, the negative impact of poor health on income and wealth appears to account for a sizable part of the correlation between financial resources and health. In samples of middle-aged and elderly Americans, Smith (1999) finds that the onset of a new illness reduces household wealth by far more than the household's out-of-pocket health expenditures, even among households with health insurance. A large share of this reduction in wealth is attributable to a decline in labor earnings. Negative health shocks strongly predict retirement and reduced labor force participation (Smith 1999, 2004, 2005; Case and Deaton 2003).

Careful studies that look for the effect of income on health find little evidence to support this causal link in samples of older individuals in developed countries. In regressions that use panel data (unlike those in section II) and control for education, wealth and lagged income do not exhibit consistent relationships with the onset of new health conditions (Adams et al. 2003; Smith 2007). Evans and Snyder (forthcoming) analyze the health effects of the social security 'notch,' which resulted in sharp changes in the benefit structure of U.S. social security in the 
1970s. Their results indicate that reductions in social security income if anything increased longevity among recipients. ${ }^{21}$

Alternative sources of evidence weigh similarly against the hypothesis that income protects adult health. Ruhm (2000, 2005) finds that recessions improve adult health, arguably because individuals engage in healthier lifestyles during downturns- - they exercise more, drink less, and smoke less, for example. These patterns probably reflect some combination of job stress and the increased opportunity cost of time during economic booms. ${ }^{22}$ Ruhm's findings challenge the accepted wisdom that income exerts a strong protective effect on health, although his results only pertain to short term fluctuations in income rather than changes in permanent income. Another test for the accepted wisdom arises from a comparison of mortality trends in the United States and Britain over the past 50 years (Deaton and Paxson 2004). Trends in adult mortality were highly correlated in the two countries, even when their income paths diverged. Instead of income, the major driver of mortality decline appears to have been medical technology.

For children, however, parental income has strong protective effects on health. Case et al. (2002) document stark associations between family income and various measures of child health. As they note, child health is less likely than adult health to affect family income, so they are somewhat more liberal in interpreting the association as causal. ${ }^{23}$ The association remains large after the authors control for household composition, race, parental education, and parental

\footnotetext{
${ }^{21}$ The Evans and Snyder (forthcoming) results contrast those of Case (2004) and Jensen and Richter (2003), who use a similar strategies to analyze the health effects of income in a developing economy (South Africa) and a transitional economy (Russia), respectively. Both find evidence that income from pension receipts improves health. ${ }^{22}$ Interestingly, Sullivan and von Wachter (2006) find that lay-offs increase mortality risk, contrasting Ruhm's results. However, the psychosocial effects of being laid off may differ from the general effects of an economic downturn.

${ }^{23}$ As corroborating evidence, Case et al. (2002) show that low birth weight babies do not reduce their mothers' labor force participation. However, Fertig (2007) finds that low birthweight children are more likely to experience family dissolution in the United States (but not in Britain). This suggests that poor child health may in fact affect a family's economic circumstance.
} 
labor force status. Moreover, it does not appear to reflect genetic confounders, health insurance access, or health behaviors. As observed in Section II, the income gradient in children's health status (reported by their parents) steepens as they grow older. Part of this steepening reflects the accumulation of health insults, especially chronic conditions, as children age. Similar results have been found in Canada (Currie and Stabile 2003).

This accumulation may continue into adulthood. A rapidly growing literature demonstrates that healthier children become healthier, wealthier adults, much in the way that they attain more schooling (see Section III). The same papers that have looked at the impact of in utero and early childhood disease on schooling also document effects on labor market outcomes (e.g., Behrman and Rosenzweig 2004; Almond 2006; Black et al. 2006; Bleakley 2007). This finding has potentially profound consequences. If household economic resources protect children's health, and their health influences their potential for economic success later in life, then child health may play a part in the intergenerational transmission of socioeconomic status. The evidence indeed suggests this is so. In Britain, for example, the number of chronic conditions endured in childhood predicts employment and occupational grade in adulthood, even after adjustment for parental socioeconomic characteristics, maternal smoking during pregnancy, birth weight, and a range of other covariates (Case et al. 2005).

Once more, these results are consistent with the evidence from developing economies. In several countries in the Americas, earnings in adulthood increased as a result of childhood exposure to malaria eradication (Bleakley 2007). Likewise, in China, birth year exposure to the Great Famine lowered adult labor force participation by seven percent (Meng and Qian 2006). In rural Indonesia, women born during years with good rainfall (and presumably good crop 
yields) own more assets in adulthood (Maccini and Yang 2007). ${ }^{24}$ Taken together, these studies lay bare the profound effects of early-life conditions on later-life economic status.

The fact that income and resources appear to affect health in early developmental stages but not later in life poses some interesting questions. What are the mechanisms by which income protects children's health, and why do they stop operating (or become less important) later in adulthood? Perhaps as individuals age, their health is best thought of as a stock that is relatively impervious to small changes in circumstance, whereas the same does not hold for children.

Whether income affects adult health remains an open question. However, the preponderance of the evidence from developed countries today suggests that income does not have a large causal effect on adult health, whereas adult health has a large effect on adult income.

\section{Rank}

Sections III and IV formulated the gradient as an individual-level phenomenon. In that framework, education, income, and wealth characterize individuals who are separated from the society in which they live. The relationships of these variables with health operate through individuals' preferences and their capacities to purchase health inputs, process information, and participate in economic life. Setups of this sort have informed much of the economic approach to health, perhaps because of their appealing simplicity; the utility function, the health production process, and the budget set all coincide with the individual, making the problem conceptually tractable.

A separate set of theories views the gradient as inherently social. Individuals of greater wealth and education enjoy better health not because of some process affecting the individual in

\footnotetext{
${ }^{24}$ Interestingly, Maccini and Yang (2007) do not find evidence of this effect for men.
} 
isolation but rather because of the individual's position in a social hierarchy. ${ }^{25}$ These theories posit that low SES in any of a number of dimensions - including education, financial resources, and occupation — produces psychosocial stress due to feelings of subordination and lack of control. Health deteriorates as a result of this stress (Brunner and Marmot 1999; Wilkinson 1999). While the education and income gradients have received a good deal of attention from economists, the specific role of rank remains primarily in the domain of other disciplines.

The key mechanism in this framework is the fight-or-flight response, a chain of biochemical and physiological reactions to threats that occurs in most vertebrates. The physiological reactions, which in humans include a heightened heart rate and a redistribution of blood away from essential organs and towards the skeletal muscles, prepare the animal to protect itself against immediate danger. However, repeated exposure to the biochemical events associated with fight-or-flight takes its toll on the body, resulting in what is known as "allostatic load" among humans. Increases in allostatic load raise mortality risk and cardiovascular disease risk, hasten cognitive and physical decline, and suppress the immune system (McEwen 1998; Seemen et al. 2001). Repeated exposure to stress is also associated with the shortening of special clusters of DNA at the ends of chromosomes, called telomeres (Epel et al. 2004). Telomere shortening is thought to be an integral part of the aging process; it is associated with heightened mortality from all causes, cardiovascular disease, and infectious disease (Cawthon et al. 2003). Much of the motivation for the literature on social hierarchies and health comes not from humans but from monkeys. A well-known example is Sapolsky's research on baboons (1993, 2004), which finds that subordinate males display higher levels of glucocortoids, hormones that are secreted in response to stress. The subordinates also perform poorly on a range of health

\footnotetext{
${ }^{25}$ Of course, the distribution of resources also matters in the theories already discussed, due to its effects on the prices of goods and knowledge. But this is different from positing that distribution directly affects health.
} 
measures, including blood pressure, cholesterol levels, and body fatness. When researchers induce changes in baboons' social standing, the same patterns occur, implying that this is not merely the result of genetic sorting. The adverse effects of subordinate social position are most visible in animals with stable social hierarchies, like baboons and humans.

In humans, the bulk of the research on the link between social hierarchies and health has concentrated on occupational measures of rank. The leading examples, the two Whitehall studies of British civil servants (Marmot et al. 1978; Marmot et al. 1991), document that civil servants with lower prestige jobs experience higher rates of mortality from cardiovascular causes and from all causes. As in the case of education, these mortality differences have behavioral precursors; higher ranking officials display a lower obesity rate, a lower propensity to smoke, and higher propensities to exercise and eat fruits and vegetables. Employment grade also associates positively with a sense of control over one's health and one's work, job satisfaction, social support, and the absence of stressful life events. Studies relating the work environment and health in settings across Europe and the United States yield comparable results. ${ }^{26}$ Given that most subjects of these studies enjoy a high degree of job security and have access to adequate earnings, common interpretations of their results place more weight on psychosocial factors than on material considerations.

A nascent body of research considers subjective measures of social status, generating findings that complement the occupation-based studies. Researchers provide subjects with a drawing of a ladder, asking them to mark the wrung that best describes their position in society. Using data from the second of the Whitehall studies, Singh-Manoux et al. (2005) show that compared with occupational grade, subjective social status more strongly predicts composite scores of physical and mental health, as well as changes in these scores. Researchers have

\footnotetext{
${ }^{26}$ See Marmot et al. (1999) for a review of studies examining the relation between the work environment and health.
} 
uncovered similar patterns in the United States (Operario et al. 2004) and Taiwan (Collins and Goldman 2008). Of course, the degree to which these associations reflect causal relationships remains an open question.

Many have extended these psychosocial theories to explain the gradients in education and financial resources. In these theories, education, income, and wealth influence health through their effects on an individuals' place in a social hierarchy. The rank-based explanation for the education gradient has not undergone much rigorous testing, although the literature cites it widely (Adler et al. 1994). It finds some support in the negative correlations between education and negative emotions, which themselves predict health status (Gallo and Matthews 2003). However, little is known about the causal mechanisms underlying these associations.

In contrast, hierarchy-based explanations for the income gradient are the subject of a voluminous literature. In this framework, a person's income matters only insofar as it distinguishes him from his neighbor. Many analysts, perhaps most notably Wilkinson (1996), couple this with the idea that subordination worsens health more than domination improves it, leading to the prediction that inequalities in income and wealth are detrimental to population health. A similar hypothesis, also argued by Wilkinson (2000), posits that inequality affects health by insulting humans' innate sense of fairness. These theories have motivated a large literature to closely examine the correlation of income inequality and health, which has been observed since the influential cross-country work of Rodgers (1979). ${ }^{27}$ Rodgers noted that among countries with equal average incomes, those with greater income inequality had lower life expectancy. He interpreted this fact in a way that contradicted much of the subsequent literature, arguing that the health-income profile was concave at the individual level, so that an extra dollar

\footnotetext{
${ }^{27}$ For a sampling of the literature on income inequality and health, see the volume edited by Kawachi et al. (1999).
} 
given to a poor person influences his health far more than the same dollar would affect a rich person's health. As a result, countries with more income inequality - and therefore more poor people-would experience worse population health outcomes. In this setup, the negative correlation between inequality and health is an artifact of aggregation; inequality per se does not affect an individual's health.

Over the ensuing years, the literature in social epidemiology downplayed this explanation, choosing instead to emphasize the role of relative income. No longer was one's absolute income the primary determinant of health, as in the Rodgers framework; rather, the more popular models saw income as a marker of relative social status. Several studies documented the correlation between income inequality and health at varying levels of geographic aggregation — ranging from countries (Wilkinson 1992), to U.S. states (Kaplan et al. 1996; Kennedy et al. 1996a, 1996b), to U.S. metropolitan areas (Lynch et al. 1998) —all understood through the lens of relative income.

However, recent economic research has cast doubt on this interpretation. ${ }^{28}$ Across U.S. states and cities, much of the association between income inequality and health disappears when analyses control for racial composition - areas more heavily inhabited by African-Americans exhibit poorer health and higher income inequality, but the latter explains very little of the former holding racial composition constant (Mellor and Milyo 2001; Deaton and Lubotsky 2003). Furthermore, the results of studies at the individual level, which consider whether regional income inequality predicts an individual's health after controlling for the individual's income, have generated mixed and fragile results (e.g., Mellor and Milyo 2002). Finally, Deaton and Paxson's (2004) analysis of mortality trends in the U.S. and Britain finds that changes in

\footnotetext{
${ }^{28}$ See Deaton (2003) for a review of the literature on income inequality and health.
} 
income inequality explain little, if any, of the mortality decline in those two countries during the second half of the $20^{\text {th }}$ century.

Given such weak evidence, Deaton concludes that: "The raw correlations that exist in (some of the) data are most likely the result of factors other than income inequality, some of which are intimately linked to broader notions of inequality or unfairness" (2003, p. 115). Notably, this does not shut the door on the relative income hypothesis. Eibner and Evans (2005) show that relative income deprivation predicts subsequent mortality at the individual level. The effects of such deprivation are likely to accumulate over the course of a lifetime, so crosssectional comparisons of current mortality and current relative income are likely to understate the true relationship. But whether or not relative income matters for health, it is not clear that it drives aggregate correlations between income inequality and population health.

Although these theories of rank, relative deprivation, and inequality are appealing - and find support in biological theory and animal experiments - they present some challenges when applied to humans. First, in large human modern societies, an individual's rank or relative position is difficult to assess. The theory emphasizes how one fares relative to some reference group. Outside of special settings like Whitehall, the relevant reference group is not clear: do individuals compare themselves to their parents? Their friends? Their neighbors? One cannot infer from the data which reference groups are important (Deaton and Paxson 2004; Manski 1993), nor is it clear that they are unique. Additionally, an individual's rank possibly varies depending on the group - a poorly paid employee of the civil service, for example, might also be the leader of a church. Another difficulty with the study of the effects of rank, as an economic model of group interaction would highlight, is that individuals have control over their rank. As emphasized by Frank (1985) and by Falk and Knell (2004), individuals to some extent choose 
the groups to which they belong (and thus their rank in those groups). ${ }^{29}$ Furthermore, even if an individual's reference group is given (for example, one's unit in the military), the individual can affect his or her rank in that group over time through behavior. In either case- - endogenous group formation or endogenous ranking - the observed correlation between rank and health is difficult to interpret. Finally, the literature has yet to come to a consensus on whether rank alone matters, or whether the distance across ranks matters as well.

The policy implications of these theories are also unclear. If rank alone determines health, what policies should be implemented to increase health? Given that individuals can choose their reference group and affect their rank, policies affecting rank alone would be unlikely to diminish rank-based health gradients. However, a possible policy prescription is to put in place programs that help individuals to mitigate the health consequences of lower rank. In his studies of animals, Sapolsky (2004) reports several factors that can mitigate the effects of stressors. The presence of social supports, the presence of outlets for frustration, the perception that an individual's situation is improving, the predictability of stressors, and an individual's perceived ability to control the onset of the stressor are a few of the factors that can allay the health effects of identical stressors. Although these mitigating factors do not point to obvious policy prescriptions, they would seem to hold the key to addressing the rank-related gradient in humans, if sufficient evidence supported the idea that low rank is an important cause of poor health.

\footnotetext{
${ }^{29}$ Note, however, that an individual may be unable to perfectly predict her within-group rank before choosing a reference group. Furthermore, that prediction may be biased (Lowenstein et al. 2003).
} 


\section{Race and Ethnicity}

A final social source of health disparities in many societies involves stratification along racial and ethnic lines. Racial and ethnic differences in health are common in many parts of the world, but their causes vary substantially from country to country. Due both to spatial limitations and to the literature's disproportionate treatment of the U.S. case, we focus exclusively on the U.S. In the United States, black adults are significantly more likely than white adults to die from a variety of causes. To give a stark example, male residents of Harlem are less likely than male Bangladeshis to survive past age 40 (McCord and Freeman 1990; Sen 1998). African American adults suffer from disproportionately high rates of mortality from all causes, cardiovascular causes, and cancer, diabetes, and stroke, and they face a higher hazard of homicide than their white counterparts (Sorlie et al. 1992; Howard et al. 2000). ${ }^{30}$ In accordance with Section II, the literature shows that adjustment for other dimensions of SES (such as education and income) only partially offsets these differences. As with education and income, racial differences are smaller among the oldest age groups. Also as with these other dimensions of SES, the differences are especially striking in children. African American infants are significantly more likely to die in their first year of life than their white counterparts (Luke and Brown 2006), and they are also more likely to be born preterm or with low birth weight (Paneth 1995). In fact, white infants born in the United States' poorest counties have superior survival to non-white infants born in the nation's wealthiest counties (Krieger et al. 2008). As shown in Section II, however, the health burden faced by black Americans does not carry to other disadvantaged ethnic groups in the United States, most notably individuals of Hispanic descent (Franzini et al. 2001).

\footnotetext{
${ }^{30}$ Black Americans are far less likely than white Americans to commit suicide, however (Howard et al. 2000).
} 
Explanations for the patterning of health along racial and ethnic lines vary. In the case of African Americans, to explain the racial disparities in health that remain after accounting for differences in education and income, many appeal to discrimination, residential segregation, and the legacy of history. ${ }^{31}$ Of course, the three are intertwined, but we can gain some insight into the problem by focusing on each separately. In recent years, the medical literature has emphasized discrimination-based accounts, with a focus on racial differences in access to health care. After adjustment for income, black Medicare beneficiaries are less likely than whites to receive mammograms and to visit physicians for ambulatory care, as well as more likely to be hospitalized, to be amputated, and to die at any given age (Gornick et al. 1996). ${ }^{32}$ This suggests that elderly African Americans may receive or seek too little preventive care, leading to increased reliance on desperate measures (like amputation) and decreased survival probabilities. However, this account does not fully square with the evidence on medical responses to specific health conditions. Peterson et al. (1997) show that blacks with coronary heart disease are less likely than whites to undergo invasive heart surgery, a difference that observable disease characteristics cannot explain. Both before and after adjustment for these disease characteristics, black patients are more likely to die than white patients. However, after further controlling for the type of treatment received, the mortality difference drops to statistically insignificant levels, suggesting that differential access to treatment plays a role in the black-white mortality gap.

Some of the racial variation in the treatment of coronary heart disease may arise from racism among physicians. In a study by Schulman et al. (1999), physicians watched videos of black and white actors complaining of chest pains and then inspected charts with clinical data for

\footnotetext{
${ }^{31}$ See Williams and Collins (1995) for an overview of racial disparities in health in the United States.

${ }^{32}$ Differential rates of amputation are partly attributable to African Americans' high prevalence of diabetes, which can lead to gangrene, the most common cause of adult amputation in industrialized countries. Nonetheless, the disproportionate burden of diabetes on blacks is not large enough to account for the entire difference in amputation.
} 
these hypothetical patients. Conditional on these clinical disease features, physicians referred white patients to cardiac catheterization with significantly higher probability than they did black patients. Of course, this result may reflect physicians using race as a signal of unobserved clinical features, rather than racism. However, there is scant evidence to suggest that the patient's race provides information to physicians over and above the clinical data that were provided to them in the study. ${ }^{33}$

Although physician discrimination may account for part of the racial disparity in access to health care in the United States, recent economic research suggests that geography may play a larger role. This research underscores racial differences between, rather than within, hospitals or provider groups. African Americans tend to reside in areas where hospitals and physicians provide lower quality care, which can explain a reasonably large share of racial differences in treatments and outcomes (Chandra and Skinner 2004). For instance, Skinner et al. (2005) examine hospital-level patterns in mortality among patients admitted for heart attacks, separating hospitals into ten deciles according to the proportion of their clientele that was black. After adjustment for observable risk factors and an array of patient and hospital characteristics (including the patient's race and the average income in the patient's zip code), patients admitted to hospitals with the greatest proportion of black patients were 18 percent more likely to die within 90 days than patients admitted to hospitals with a disproportionately white clientele. The geography of health care plays an important part in producing racial differences in health. However, it cannot entirely explain these differences; for example, the Peterson et al. (1997) study of racial differences in the treatment of coronary heart disease took place in a single hospital.

\footnotetext{
${ }^{33}$ Research does suggest that coronary catheterization may have different effects on men and women (e.g., Loop et al. 1983). However, the referral differences in the Schulman et al. (1999) study were in fact larger among women.
} 
The new focus on geography also relates to a more established literature on the health effects of residential segregation and concentrated urban poverty. Concentrated poverty is thought to erode social support, cause neglect of the physical environment, and increase crime, all of which have been hypothesized to affect mental and physical health. Sociologists Collins and Williams (1999) report that among African Americans, increased residential isolation from whites is associated with increased mortality risk, and the association is robust to adjustment for black poverty rates. This might in part reflect the geography of health care, but the same pattern is observed for homicide, for which health care is unlikely to play a role. Nevertheless, as with any observational study, the estimates should be interpreted with caution. In particular, the analysis does not fully control for the decision of people where to live. Experimental evidence from the Moving to Opportunity program (Kling et al. 2007) is therefore instructive. The program offered housing vouchers to a randomized subset of poor households, leading these households to move to lower poverty areas. The results indicate that moving to lower poverty areas induced improvements in mental health, but the estimates for physical health and youth risk behavior are mixed. Especially disturbing are the results for young males, whose health and engagement in risky behaviors (such as drug and alcohol use) deteriorated after moving to lower poverty areas. These findings may imply that the negative psychosocial effects of residential disruption outweigh positive neighborhood effects among adolescent males, but at any rate, they do not weigh in favor of neighborhood-based explanations for racial health disparities.

Black-white differences in health have a long history in the United States. In 1900, a full 35 years after the abolition of slavery, roughly three black children died for every two deceased white children (Ewbank 1987). Although racial differences in mortality narrowed in the first half of the twentieth century, especially among infants (Troesken 2004), the infant mortality gap 
remained stubbornly large over the subsequent 50 years, even as income-based differences in infant mortality diminished (Krieger et al. 2008). Some have speculated that the contemporary disparities may have historical origins. One theory along these lines posits that the circumstances surrounding the capture of slaves in Africa, the transatlantic slave voyage, and slavery in the United States led to selective survival among Africans genetically predisposed to conserve salt and water (Wilson and Grim 1991). These genetic traits are associated with high blood pressure, thus offering an explanation for the high rates of hypertension and cardiovascular disease today. This theory is still being debated (Jackson 1991; Curtin 1992; Barghaus et al. 2007). Another historical theory involves the early $20^{\text {th }}$ century rise in African Americans' propensities to smoke and abuse alcohol, which accompanied the Great Northern Migration. Williams and Collins (1995) attribute this shift to the centrality of drinking taverns to Northern social life and the alienation of blacks in Northern cities, suggesting that these had persistent effects on substance use among African Americans. Still other work on the legacy of history draws on the 1960s desegregation of hospitals in the U.S. South, which improved the health of black infants (Almond et al. 2008). The healthier infant girls grew up to be healthier women, who now mother healthier infants of their own (Almond and Chay 2006). The injustices of the past may thus affect those born in the present.

Black-white mortality differences are especially salient because the U.S. Hispanic population, though currently facing socioeconomic disadvantage of a magnitude similar to that of black America, enjoys survival rates that are on par with, or even slightly higher than, survival rates among non-Hispanic whites (Sorlie et al. 1993; Liao et al. 1998; Elo et al. 2004). This phenomenon is known as the "Hispanic Paradox." As shown in Section II, Hispanics are slightly more likely to die than non-Hispanic whites in early adulthood, but they are also less likely to die 
in old age (Liao et al. 1998). Compared to the infants of non-Hispanic whites, the infants of Hispanic women face similar rates of low birth weight and infant mortality (Paneth 1995).

Selection mechanisms and data problems may explain some of this pattern. First, the mortality statistics for Hispanics may suffer from age misreporting (Elo and Preston 1997) and undercounts of deaths (Smith and Bradshaw 2006). Second, Latino immigrants may return home to die in their countries of origin, thus disappearing from U.S. mortality data and creating what is known as "salmon bias." However, this cannot tell the whole story; Cuban immigrants to the United States, who for geopolitical reasons are unlikely to return home, enjoy a survival advantage that is comparable to that of their Hispanic counterparts (Abraído-Lanza et al. 1999). Third, those who choose to migrate to the United States may be inherently healthier than their non-migrating compatriots (Marmot et al. 1984). Jasso et al. justify this explanation by noting that "because the health of the U.S. native born is so far in excess of those in most migrant sending countries, if migrants to the U.S. have better health than the U.S. native born, they surely have better health than those who stayed in the sending countries" (2004, pp. 234-235). This line of reasoning rests on the rather strong assumption that the health of migrants would have been similar had they remained in their sending countries. Here too, however, more careful analyses cast doubt on the theory. In Mexico, for example, health is at most a weak predictor of subsequent migration (Rubalcava et al. 2008). Among urban women, those with better health exhibit a slightly higher propensity to emigrate to the United States, but this pattern does not hold among rural women or among men. ${ }^{34}$ While this does not necessarily disprove the "healthy migrant hypothesis," neither does it weigh in its favor.

\footnotetext{
${ }^{34}$ In fact, Rubalcava et al. (2008) find that Mexican men who self-report better health are less likely to migrate. They advise against attaching too much significance in this finding, however, due to confusion over the meaning of the health status question.
} 
As in the cases of education and rank, behavioral differences can take us some of the remaining distance in explaining the Hispanic Paradox. Compared to non-Hispanic whites, Latinos of both sexes are less likely to drink excessively, and Latina women are less likely to smoke (Pérez-Stable et al. 1994). These differences are especially large for recent immigrants. Several risk behaviors increase in prevalence with the length of residence in the United States, as well as across generations, a process known as "acculturation." Compared to their more acculturated counterparts, newcomers consume more fiber, breastfeed more, and are less likely to abuse alcohol, tobacco, and illicit drugs (Vega and Amaro 1994; Lara et al. 2005). Furthermore, children of first generation women are less likely than children of second generation women to be born with low birth weight or to die in the first year of life. This is partially because second generation mothers have a higher propensity to smoke and drink (Landale et al. 1999). Notably, these patterns may reflect changes in the composition of immigrant cohorts over time, rather than actual acculturation. To our knowledge, researchers have yet to sort out this issue.

To some extent, race and ethnicity are markers of genetic differences across groups. But racial and ethnic differences in health likely result in large part from non-genetic sources, such as differences in behavior, access to care, social and cultural norms, and discrimination. The task of unraveling the mechanisms that lead to racial and ethnic inequalities is important for policy. If all racial differences are driven by genetic differences, policy should encourage genetic research that identifies genes associated with particular diseases or pre-disposition to disease. If the differences arise due to other causes, then more direct action might be more appropriate. For example, if differences in health are driven by differences in access to quality care hospitals, then one might seek to increase access to those hospitals or to improve quality across hospitals. Some 
of the explanations for racial and ethnic differences bring us back to debates about education, income, and rank. Others do not. If prejudice plays a large role, then policy might appropriately emphasize laws intended to minimize unequal treatment.

\section{Conclusion: Towards a Unified Theory}

The literature we review shows clearly that socioeconomic status and health are strongly related, in both industrialized and developing countries, in both welfare states and liberal democracies. That said, the mechanisms linking the various dimensions of SES to health are diverse. Some dimensions of SES cause health, some are caused by health, and some are mutually determined with health; some fall into all three categories at once.

These differential patterns of causality make a single theory of socioeconomic gradients in health difficult to imagine. We suspect, though, that the right theory will emphasize the

lifecycle. In childhood, parental resources - education and income, for example - have a potent effect on health. Parental membership in a low racial or ethnic group may also influence health, in part through its impact on parental resources and in part outside of that. Parenting behaviors, which themselves are influenced by SES, play some role in the determination of child health (Case and Paxson 2002).

Once childhood health is set, the effect of economic resources on health diminishes. In most of adulthood, income and wealth no longer appear to have a large affect health. Education continues to be a powerful determinant of health, but to a great extent because of its impact on behaviors rather than its association with resources. Exactly why education affects health behaviors remains unclear, but much of the story seems to hinge on the ability to process new 
information and to take advantage of new technologies. The lasting impact of childhood also begins to emerge, as healthier children obtain more education.

Feedbacks start in adulthood as well. Unhealthy adults earn less, spend less time in the labor force, and retire earlier. Insults to child health may persist into adulthood, constraining adults in the labor market. Similarly, the detrimental effect of childhood illness on schooling leaves some adults deficient in human capital, and their children worse off as well. Thus emerges the intergenerational element of the theory; poor childhood health begets limited means in adulthood, which in turn begets poor childhood health for the next generation.

Low social status - whether through membership in a disadvantaged racial group or through low rank in a hierarchy — may also cause poor health in adulthood, but the mechanisms here remain poorly understood. In some cases, broader societal forces are at work: for example, when geographic sorting prohibits one group from living in the vicinity of quality health care facilities, or when direct discrimination leads to similar outcomes. In others, the legacies of historical discrimination and injustice loom large, possibly affecting even the genetic makeup of historically disadvantaged groups. In still other cases, current position in society may influence an individual's health through a range of psychosocial mechanisms.

Apart from the substantive findings of the literature we review, we have also remarked on its interdisciplinary nature. Economists have made substantial contributions empirically and theoretically, using the tools of modern economics. This has been possible in part because economists have focused on each component of SES separately, an approach which is more suitable to finding causal relationships and also to implementing policy. However, several aspects of the SES-health gradient remain understudied by economists - for example, health differences by rank. Group dynamics are inherently harder to understand than individual 
behavior. And economists need to look to other disciplines for an understanding of the biology behind these findings we observe.

Because the exact mechanisms underlying the link between socioeconomic status and health are not completely clear, the optimal policy response is difficult to determine. One appealing strategy is to enact policies focused on children. Improving childhood health may lead to improved socioeconomic outcomes later in life in addition to current health improvements. Additionally, if the effect of education operates primarily through cognition and higher order thinking, then government efforts would be better directed at general schooling, rather than health-specific information campaigns. As one component of research on socioeconomic status and health, it would be valuable to experiment with policies targeted along these lines. 


\section{References}

Abraido-Lanza, A.F., B.P. Dohrenwend, D.S. Ng-Mak and J.B. Turner. 1999. The Latino mortality paradox: A test of the 'salmon bias' and healthy migrant hypotheses. American Journal of Public Health 89: 1543-1548.

Adler, N. E., T. Boyce, M.A. Chesney, S. Cohen, S. Folkman, R.L. Kahn, and S.L. Syme. 1994. Socioeconomic Status and Health, the Challenge of the Gradient. American Psychologist 49(1): $15-24$.

Almond, D. 2006. Is the 1918 influenza pandemic over? Long-term effects of in utero influenza exposure in the post-1940 U.S. population. Journal of Political Economy 114: 562-712.

Almond, D. and K. Chay. 2006. The long-run and intergenerational impact of poor infant health: Evidence from cohorts born during the civil rights era. Mimeo, Columbia University.

Almond, D., K. Chay and M. Greenstone. 2008. Civil rights, the war on poverty, and black-white convergence in infant mortality in the rural South and Mississippi. American Economic Review, forthcoming.

Arendt, J.N. 2005. Does education cause better health? A panel data analysis using school reform for identification. Economics of Education Review 24:149-160.

Banks, J., M. Marmot, Z. Oldfield, and J.P. Smith. Forthcoming. The SES health gradient on both sides of the Atlantic. In D.A. Wise, ed., Developments in the Economics of Aging. Chicago: University of Chicago Press.

Barghaus, K.M., D.M. Cutler, R.G. Fryer, and E.L. Glaeser. 2008. Understanding racial differences in health. Harvard University, mimeo.

Behrman, J.R., and M.R. Rosenzweig. 2004. Returns to birthweight. Review of Economics and Statistics 86(2): 586-601.

Black, S.E., P.J. Devereux, and K.G. Salvanes. 2007. From the cradle to the labor market? The effect of birth weight on adult outcomes. Quarterly Journal of Economics 122(1): 409-439.

Bleakley, H. 2007. Disease and development: Evidence from hookworm eradication in the American South. Quarterly Journal of Economics 122(1): 73-117.

Bleakley, Hoyt. 2006. Malaria in the Americas: A retrospective analysis of childhood exposure. Mimeo, University of Chicago.

Bobonis, G.J., E. Miguel, and C.P. Sharma. 2006. Iron deficiency anemia and school participation. Journal of Human Resources 41(4): 692-721. 
Brunner, E., and M.G. Marmot. 1999. Social organization, stress, and health. In M. Marmot and R.G. Wilkinson, eds., Social Determinants of Health. Oxford: Oxford University Press, pp. 17-43.

Bzostek, S., N. Goldman, and A. Pebley. 2007. Why do Hispanics in the U.S.A. report poor health? Social Science and Medicine 65(5): 990-1003.

Case, A., A. Fertig and C. Paxson. 2005. The lasting impact of childhood health and circumstance. Journal of Health Economics 24: 365-389.

Case, A., D. Lubotsky, and C. Paxson. 2002. Economic status and health in childhood: the origins of the gradient. American Economic Review 92(5): 1308-1334.

Case, A., and C. Paxson. 2002. Parental Behavior and Child Health. Health Affairs 21(2): 164178.

Cawthon, R.M., K.R. Smith, E. O'Brien, A. Sivatchenko and R.A. Kerber. 2003. Association between telomere length in blood and mortality in people aged 60 years or older. Lancet 361(1): 393-395.

Chandra, A., and J. Skinner. 2004. Geography and health disparities. In N.B. Anderson, R. Bulatao, and B. Cohen, eds., Critical Perspectives on Racial and Ethnic Differences in Health in Late Life. Washington, D.C.: National Research Council of the National Academies, pp. 604-640.

Clark, D., and H. Royer. 2007. "The effect of education on longevity: Evidence from the United Kingdom. Mimeo, Case Western Reserve University.

Collins, A.L. and N. Goldman. 2008. Perceived social position and health in older adults in Taiwan. Social Science and Medicine 66(3): 536-544.

Collins, C.A. and D.R. Williams. 1999. Segregation and mortality: The deadly effects of racism? Sociological Forum 14(3): 495-523.

Curtin, P.D. 1992. The slavery hypothesis for hypertension among African Americans: the historical evidence. American Journal of Public Health 82: 1681-1686.

Cutler, D.M., and A. Lleras-Muney. 2007a. Education and health: evaluating theories and evidence. In J.S. House, R.F. Schoeni, G.A. Kaplan, and H. Pollack, eds., The Health Effects of Social and Economic Policy, New York: Russell Sage Foundation.

Cutler, D.M. and A. Lleras-Muney. 2007b. Understanding differences in health behaviors by education. Mimeo, Princeton University.

Currie, J., and M. Stabile. 2003. Socioeconomic status and health: Why is the relationship stronger for older children? American Economic Review 93(5): 1813-1823. 
Deaton, A., D. Cutler, and A. Lleras-Muney. 2006. The determinants of mortality. Journal of Economic Perspectives 20(3): 97-120.

Deaton, A. 2003. Health, inequality, and economic development. Journal of Economic Literature 41(1): 113-158.

Deaton, A. and C. Paxson. 2004. Mortality, income, and income inequality over time in Britain and the United States. In D.A. Wise, ed., Perspectives on the Economics of Aging. Chicago: University of Chicago Press, pp. 247-279.

Deaton, A. and D. Lubotsky. Mortality, inequality and race in American cities and states. Social Science and Medicine 56(6): 1139-1153.

Deschênes, O. 2001. Unobserved ability, comparative advantage and the rising return to education in the United States: A cohort-based approach. Industrial Relations Section Working Paper No. 465, Princeton University.

Eibner, C. and W.N. Evans. 2005. Relative deprivation, poor health habits, and mortality. Journal of Human Resources 40(3): 592-620.

Elo, I. T. and S.H. Preston. 1996. Educational differentials in mortality: United States, 1979-85. Social Science and Medicine 42(1): 47-57.

Elo, I.T. and S.H. Preston. 1997. Racial and ethnic differences in mortality at older ages. In L. Martin and B. Soldo, eds., Racial and Ethnic Differences in the Health of Older Americans. Washington, DC: National Academy Press, pp. 10-42.

Elo, I.T., C.M. Turra, B. Kestenbaum, and B.R. Ferguson. 2004. Mortality among elderly Hispanics in the United States: Past evidence and new results. Demography 41: 109-128.

Epel, E.S., E.H. Blackburn, J. Lin, et al. 2004. Accelerated telomere shortening in response to life stress. PNAS 101(49): 17,312-17,315.

Evans, W.N. and S. Snyder. 2007. The impact of income on mortality: evidence from the social security notch. Review of Economics and Statistics, forthcoming.

Falk, Armin, and Markus Knell. 2004. Choosing the Joneses: On the endogeneity of reference groups. Scandinavian Journal of Economics 106(3): 417-435.

Fan, J. 1992. Design-adaptive nonparametric regression. Journal of the American Statistical Association 87: 998-1004.

Fan, J. M. Farmen, and I. Gijbels. 1998. Local maximum likelihood estimation and inference. Journal of the Royal Statistical Society: Series B (Statistical Methodology). 60(3): 591-608. 
Field, E., O. Robles and M. Torero. 2007. Iodine deficiency and schooling attainment in Tanzania. Mimeo, Harvard University.

Frank, R.H. 1985. Choosing the Right Pond. New York: Oxford University Press.

Franzini, L., J.C. Ribble and A.M. Keddie. 2001. Understanding the Hispanic Paradox. Ethnicity and Disease 11(3): 496-518.

Gallo, L.C., and K.A. Matthews. 2003. Understanding the association between socioeconomic status and physical health: Do negative emotions play a role? Psychological Bulletin 129(1): $10-51$.

Glied, S. and A. Lleras-Muney. 2008. Health inequality, education, and medical innovation. Demography, forthcoming.

Gornick, M.E., E.W.Eggers, T.W. Reilly, et al. 1996. effects of race and income on mortality and use of services among Medicare beneficiaries. New England Journal of Medicine 335(11): 791-799.

Grossman, M. 1972. The Demand for Health—A Theoretical and Empirical Investigation. New York: National Bureau of Economic Research.

Grossman, M. 2008. Education and non-market outcomes. In E. Hanushek and F. Welch, eds., Handbook of the Economics of Education. Amsterdam: North-Holland, Elsevier Science, forthcoming.

Haines, M.R. 2001. The urban mortality transition in the United States: 1800-1940. Annales de Demographie Historique: 33-64.

Harris, B. 2004. Public health, nutrition, and the decline of mortality: The McKeown thesis revisited. Social History of Medicine 17(3): 379-407.

Huisman, M., Kunst, A., Bopp, M., et al. 2005. Educational inequalities in cause-specific mortality in middle-aged and older men and women in eight western European populations. Lancet 365(9458): 493-500.

Idler, E.L., and Y. Benyamini. 1997. Self-rated health and mortality: A review of twenty-seven community studies. Journal of Health and Social Behavior 38(1): 21-37.

Jackson, F.L.C. 1991. An evolutionary perspective on salt, hypertension, and human genetic variability. Hypertension 17(1, S1): 129-132.

Jasso, G., D.S. Massey, M.R. Rosenzweig, and J.P. Smith. 2004. Immigrant health: Selectivity and acculturation. In N.B. Anderson, R. Bulatao, and B. Cohen, eds., Critical Perspectives on Racial and Ethnic Differences in Health in Late Life. Washington, D.C.: National Research Council of the National Academies, pp. 227-266. 
Jayachandran, S. and A. Lleras-Muney. Forthcoming. Life expectancy and human capital investment: evidence from maternal mortality declines. Quarterly Journal of Economics.

Kawachi, I., B.P. Kennedy and R.G. Wilkinson. 1999. The Society and Population Health Reader: Volume 1: Income Inequality and Health. NY: New Press.

Kitagawa, E. M. and P. M. Hauser (1973) Differential Mortality in the United States: A Study in Socioeconomic Epidemiology, Cambridge, MA: Harvard University Press.

Kling, J., J.B. Liebman, and L.F. Katz. 2007. Experimental analysis of neighborhood effects. Econometrica 75(1): 83-119.

Krieger, N., D.H. Rehkoph, J.T. Chen, P.D. Waterman, E. Marcelli, and M. Kennedy. 2008. The fall and rise of U.S. inequalities in premature mortality: 1960-2002. PLoS Medicine 5(2): $227-241$.

Landale, N.S., R.S. Oropresa, and B.K. Gorman.1999. Immigration and infant health: Birth outcomes of immigrant and native-born women. In D.J. Hernandez, ed., Children of Immigrants. Washington, D.C.: National Academy of Sciences Press, pp. 244-285.

Lara, M., C. Gamboa, M.I. Kahramanian, L.S. Morales, and D.H. Bautista. 2005. Acculturation and Latino health in the United States: A review of the literature and its sociopolitical context. Annual Review of Public Health 26: 367-397.

Liao, Y., R.S. Cooper G. Cao, R. Durazo-Arvizu, J.S. Kaufman, A. Luke, and D.L. McGee. 1998. Mortality patterns among adult Hispanics: Findings from the NHIS, 1986 to 1990. American Journal of Public Health 88(2): 227-232.

Link, B.G and J. Phelan. 1995. Social conditions as the fundamental causes of disease. Journal of Health and Social Behavior 35(Extra Issue): 80-94.

Lleras-Muney, A. 2005. The relationship between education and adult mortality in the United States. Review of Economic Studies 72: 189-221.

Loop, F.D., L.R. Golding, J.P. MacMillan, D.M. Cosgrove, B.W. Lytle, and W.C. Sheldon. 1983. Coronary artery surgery in women compared with men: analyses of risks and longterm results. Journal of the American College of Cardiology 1: 383-390.

Loewenstein, G., T. O'Donoghue, and M. Rabin. 2003. Projection bias in predicting future utility. Quarterly Journal of Economics 118(4): 1209-1248.

Lucas, A. 2005. Economic effects of malaria eradication: Evidence from the malarial periphery. Mimeo, Brown University. 
Lemieux, T. 2006. The Mincer equation thirty years after Schooling, Experience, and Earnings. In S. Grossbard-Shechtman, ed., Jacob Mincer, A Pioneer of Modern Labor Economics. New York: Springer, pp. 127-148.

Luke, B., M.B. Brown. 2006. The changing risk of infant mortality by gestation, plurality, and race: 1989-1991 versus 1999-2001. Pediatrics 118: 2488-2497.

Lynch, J.W., G.A. Kaplan, and E.R. Pamuk. 1998. Income inequality and mortality in metropolitan areas of the United States. American Journal of Public Health 88: 1074-1080.

Lynch, S.M. 2003. Cohort and life course patterns in the relationship between education and health: A hierarchical approach. Demography 40(2):309-331.

Maccini, S. and D. Yang. 2007. Under the weather: Health, schooling and socio-economic consequences of early life rainfall. Mimeo, University of Michigan.

Mackenbach, J.P. 2006. Health Inequalities: Europe in Profile. London: U.K. Department of Health.

Manski, C.F. Identification of endogenous social effects: The reflection problem. Review of Economic Studies 60(3): 531-542.

Marmot M.G., G. Rose, M. Shipley, and P.J.S. Hamilton. 1978. Employment grade and coronary heart disease in British civil servants. Journal of Epidemiology and Community Health 1978 32: 244-249.

Marmot, M.G., A.M. Adelstein, and L. Bulusu. 1984. Lessons from the study of immigrant mortality. Lancet 2: 1455-1457.

Marmot, M.G., et al. 1991. Health inequalities among British civil servants: The Whitehall II study. Lancet 337(8754): 1387-1393.

Marmot, M.G., J. Siegrist, T. Theorell, and A. Feeney. 1999. Health and the psychosocial environment at work. In M. Marmot and R.G. Wilkinson, eds., Social Determinants of Health. Oxford: Oxford University Press, pp. 105-131.

Mathews, T.J., and K.G. Keppel. 2005. Racial/ethnic disparities in infant mortality--United States, 1995-2002. Journal of the American Medical Association 294: 298-299.

Mazumder, B. 2008. Does education improve health? A reexamination of the evidence from compulsory schooling laws. Federal Reserve Bank of Chicago Economic Perspectives Q2: 216.

McCord, C., and H.P. Freeman. 1990. Excess mortality in Harlem. New England Journal of Medicine 322: 173-177. 
McDonough, P., G.J. Duncan, D. Williams and J. House. 1999. Income dynamics and adult mortality in the United States, 1972 through 1989. American Journal of Public Health 87(9): 1476-1483.

McEwen, B.S. 1998. Protective and damaging effects of stress mediators. New England Journal of Medicine 338(3): 1771-1779.

Mellor, J.M. and J. Milyo. 2001. Reexamining the evidence of an ecological association between income inequality and health. Journal of Health Politics, Policy, and Law 26: 487-522.

Mellor, J.M. and J. Milyo. 2002. Income inequality and health status in the United States: Evidence from the Current Population Survey. Journal of Human Resources 37(3): 510-539.

Meng, X. and N. Qian. 2006. The long run health and economic consequences of famine on survivors: Evidence from China's Great Famine. IZA Discussion Paper 2471.

Miguel, E. and M. Kremer. 2004. Worms: Identifying impacts on education and health in the presence of treatment externalities. Econometrica 72(1): 159-217.

Mincer, J. 1997. Changes in wage inequality, 1970-1990. Research in Labor Economics 16: 118.

Mosk, C. and S. R. Johansson. 1986. Income and mortality: Evidence from Modern Japan. Population and Development Review 12(3): 415-440.

Molla, M.T., J.H. Madans, and D.K. Wagener. 2004. Differentials in adult mortality and activity limitation by years of education in the United States at the end of the 1990s. Population and Development Review 30(4): 625-646.

Operario, D., N.E. Adler, and D.R. Williams. 2004. Subjective social status: Reliability and predictive utility for global health. Psychology and Health 19(2): 237-246.

Oreopoulos, P. 2007. Do dropouts drop out too soon? Wealth, health and happiness from compulsory schooling. Journal of Public Economics 91(11-12): 2213-2229.

Paneth, N. 1995. The problem of low birthweight. Future of Children 5:19-34.

Pérez-Stable, E.J., G. Marín, and B.V. Marín. 1994. Behavioral risk factors: a comparison of Latinos and non-Latino whites in San Francisco. American Journal of Public Health 84: 971976.

Peterson E.D., L.K. Shaw LK, E.R. DeLong, D.B. Pryor, R.M. Califf, D.B. Mark. 1997. Racial variation in the use of cardiac revascularization procedures. New England Journal of Medicine 336: 480-486. 
Rodgers, G.B. 1979. Income and inequality as determinants of mortality: an international crosssection analysis. Population Studies 33(3): 343-51.

Ross, C.E. and C. Wu. 1995. The links between education and health. American SociologicalReview 60: 719-745.

Rubalcava, L.N., G.M. Teruel, D. Thomas, and N. Goldman. 2008. The healthy migrant effect: New findings from the Mexican Family Life Survey. American Journal of Public Health 98(1): 78-84.

Ruhm, C.J. 2000. Are recessions good for your health? Quarterly Journal of Economics 115(2): 617-650.

Ruhm, C.J. 2005. Healthy living in hard times. Journal of Health Economics 24(2): 341-63.

Sapolsky, R.M. 1993. Endocrinology alfresco: Psychoendocrine studies of wild baboons. Recent Progress in Hormone Research 48: 437-468.

Sapolsky, R.M. 2004. Why Zebras Don't Get Ulcers. An updated guide to stress, stress-related diseases, and coping (3rd Edition). New York: Freeman.

Schulman, K.A., et al.. 1999. The effect of race and sex on physicians' recommendations for cardiac catheterization. New England Journal of Medicine 340: 618-626.

Seeman, T.E., B.S. McEwen, J.W. Rowe, and B.H. Singer. 2001. Allostatic load as a marker of cumulative biological risk: MacArthur studies of successful aging. Proceedings of the National Academy of Sciences 98(8): 4770-4775.

Sen, A.K. 1998. Mortality as an indicator of economic success and failure. Economic Journal 108: $1-25$.

Singh-Manoux, A., M.G. Marmot and N.E. Adler. 2005. Does subjective social status predict health and change in health status better than objective status? Psychosomatic Medicine 67: $855-861$.

Skinner, J., A. Chandra, D. Staiger, J. Lee and M. McClellan.2005. Mortality after acute myocardial infarction in hospitals that disproportionately treat black patients. Circulation 112: $2634-2641$.

Smith, D.P., and B.S. Bradshaw. 2006. Rethinking the Hispanic Paradox: Death rates and life expectancy for US non-Hispanic white and Hispanic populations. American Journal of Public Health 96: 1686-1692.

Smith, J.P. 1999. Healthy bodies and thick wallets: The dual relation between health and economic status. Journal of Economic Perspectives 13(2): 145-166. 
Smith, J.P. 2004. Unraveling the SES-health connection. Population and Development Review 30(Supplement): 108-132.

Smith, J.P. 2005. Consequences and predictors of new health events. In D.A. Wise, ed., Analyses in the Economics of Aging. Chicago: University of Chicago Press, pp. 213-237.

Smith, J.P. 2007. The impact of social economic status on health over the life-course. Journal of Human Resources 42: 739-764.

Sorlie, P., E. Rogot, R. Anderson, N.J. Johnson, and E. Backlund. 1992. Black-white mortality difference by family income. Lancet 340: 346-350.

Sorlie, P.D., E. Backlund, N.J. Johnson, and E. Rogot. 1993. Mortality by Hispanic status in the United States. Journal of the American Medical Association 270: 2464-2468.

Spasojevic, J. 2003. Effects of education on adult health in Sweden: Results from a natural experiment. PhD dissertation, City University of New York Graduate Center, New York.

Strauss, J. and D. Thomas. 1998. Health, nutrition, and economic development. Journal of Economic Literature 36(2): 766-817.

Sullivan, D. and T. von Wachter. 2006. Mortality, mass-Layoffs, and career outcomes: An analysis using administrative data. Mimeo, Columbia University.

Troesken, W. 2004. Water, Race, and Disease. Cambridge, MA: MIT Press.

Vega WA, Amaro H. 1994. Latino outlook: good health, uncertain prognosis. Annual Review of Public Health 15: 39-67.

Wilkinson, R. 1990. Income distribution and mortality: a 'natural' experiment. Sociology of Health and Illness 12: 391-412.

Wilkinson, R.G. 1996. Unhealthy societies: the affliction of inequality. London: Routledge.

Wilkinson, R.G. 1999. Health, hierarchy and social anxiety. Annals of the New York Academy of Sciences 896: 48-63.

Wilkinson, R.G. 2000. Mind the Gap: Hierarchies, Health, and Human Evolution. London: Weidenfeld and Nicolson.

Williams, D.R. and C. Collins. 1995. U.S. socioeconomic and racial differences in health: patterns and explanations. Annual Review of Sociology 21:349-86.

Wilson, T.W., and C.E. Grim. 1991. Biohistory of slavery and blood pressure differences in blacks today. Hypertension 17(1, S1): 122-128. 
Figure 1: Education and Mortality among Adults over 40, U.S. and Europe

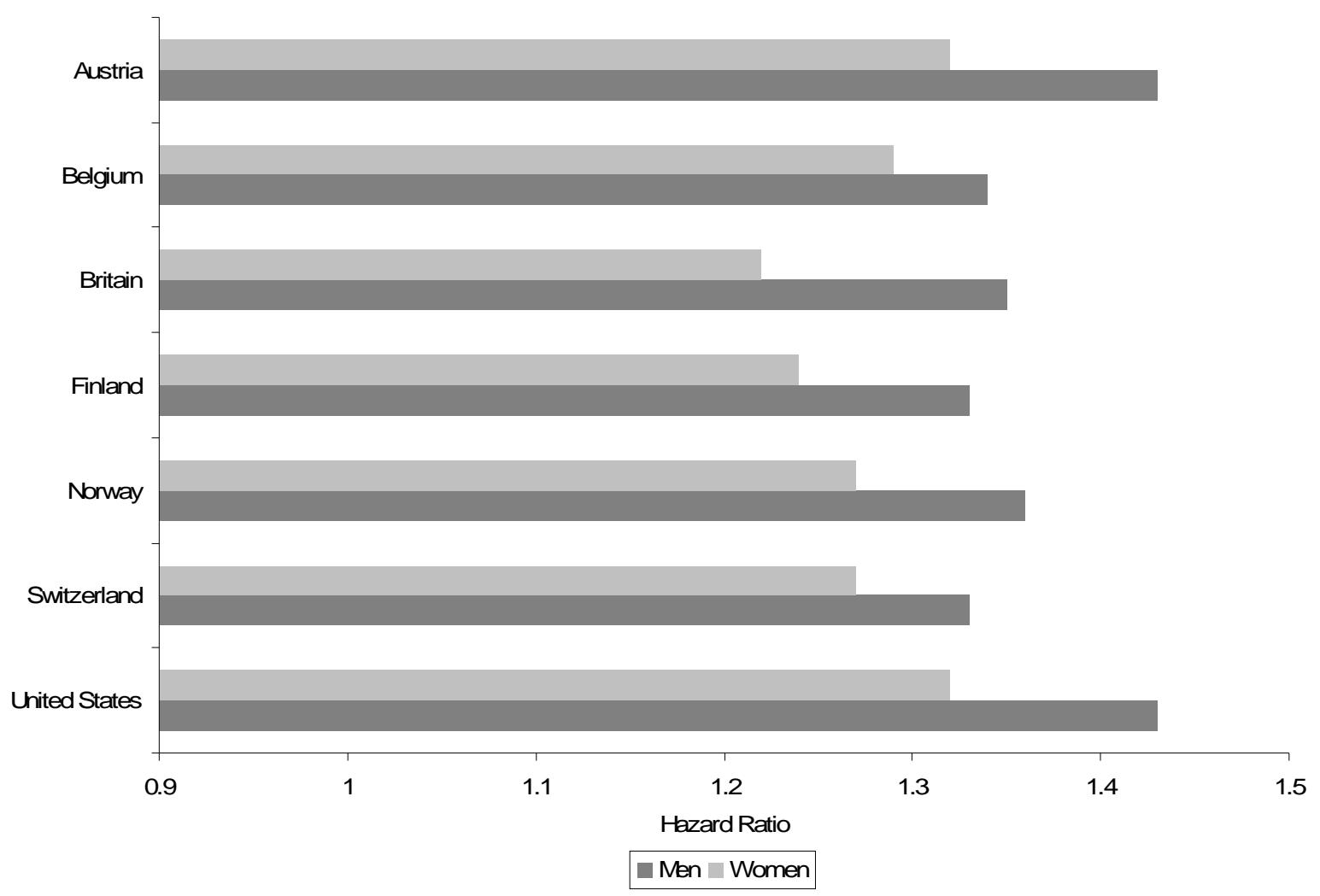

Notes: The bars represent the increase in annual mortality risk associated with having less than upper-secondary education (compared with at least upper-secondary education). All hazard ratios are adjusted for age. The Swiss sample is representative of only German-speaking regions of Switzerland, the British sample includes only England and Wales. The estimates for European countries are drawn from Huisman et al. (2005), while those for the U.S. are from Cox proportional hazards regressions using the 1990 National Health Interview Survey (NHIS) with mortality follow-up until 2002. Section II provides further details on the NHIS sample. 
Figure 2a: Education and Mortality, U.S. Adults over 25, NHIS 1986-1995

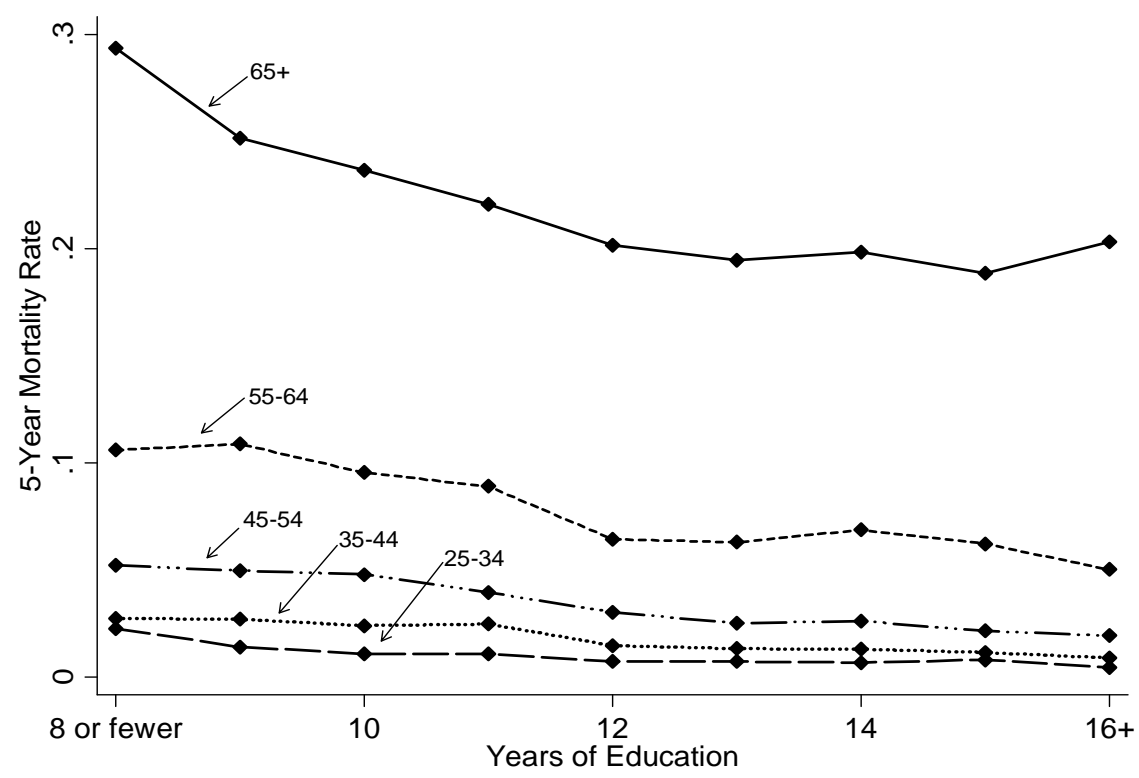

Notes: The estimated mortality rates are weighted using the survey weights provided by the NHIS. 5-year mortality is defined as death before the start of the sixth year following the survey year.

Figure 2b: Education and Self-Reported Health, U.S. Adults over 25, NHIS 1986-1995

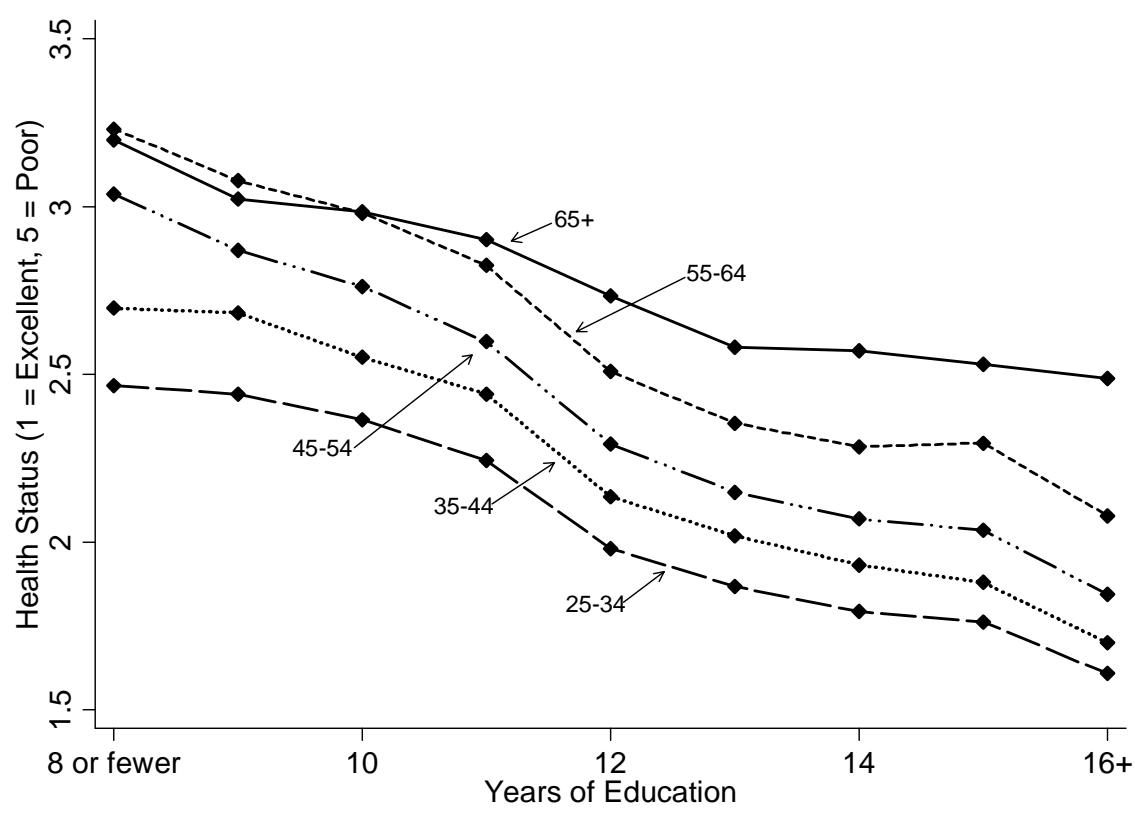

Notes: The means are weighted using the survey weights provided by the NHIS. 
Figure 3a: Income and Mortality, U.S. Adults over 25, NHIS 1986-1995

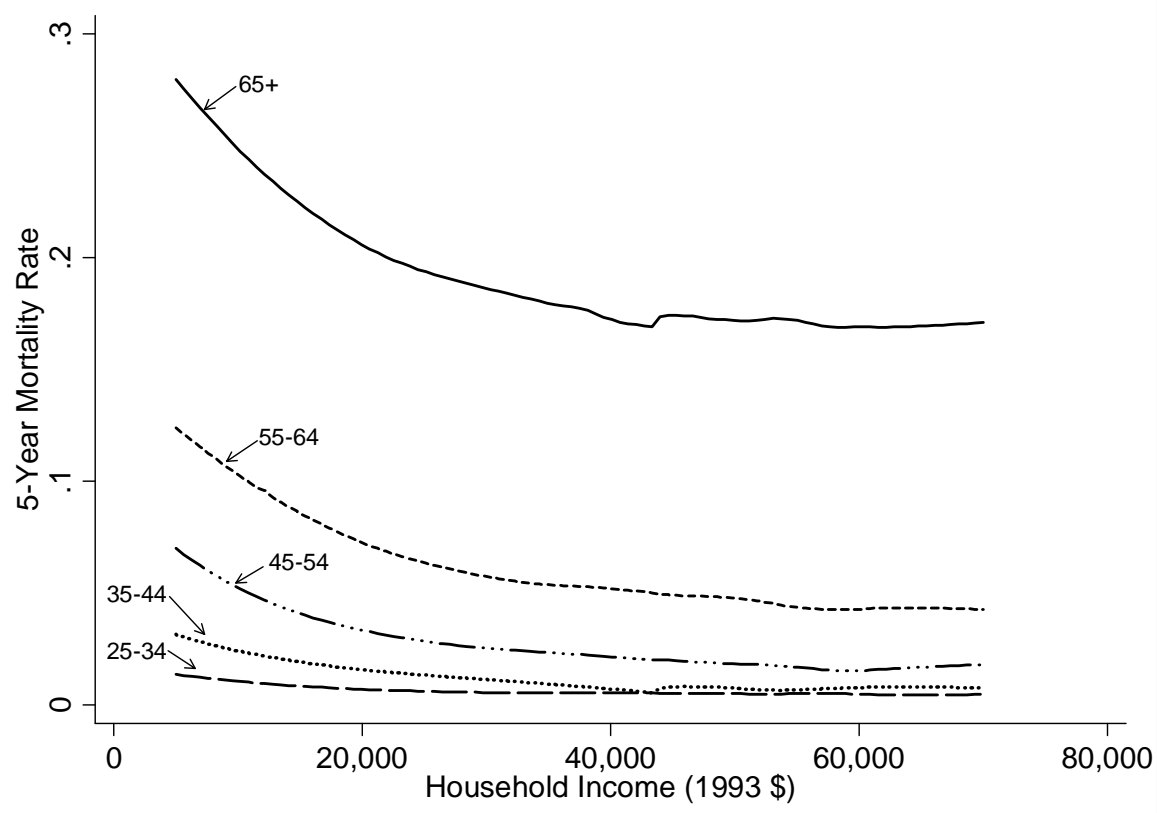

Notes: The curves are local logistic regression estimates. The regressions are weighted using the survey weights provided by the NHIS. Household income is reported in income brackets in the NHIS; it is imputed here from the March CPS of the same year as the mean income in the income bracket and education cell of the household head.

Figure 3b: Income and Self-Reported Health, U.S. Adults over 25, NHIS 1986-1995

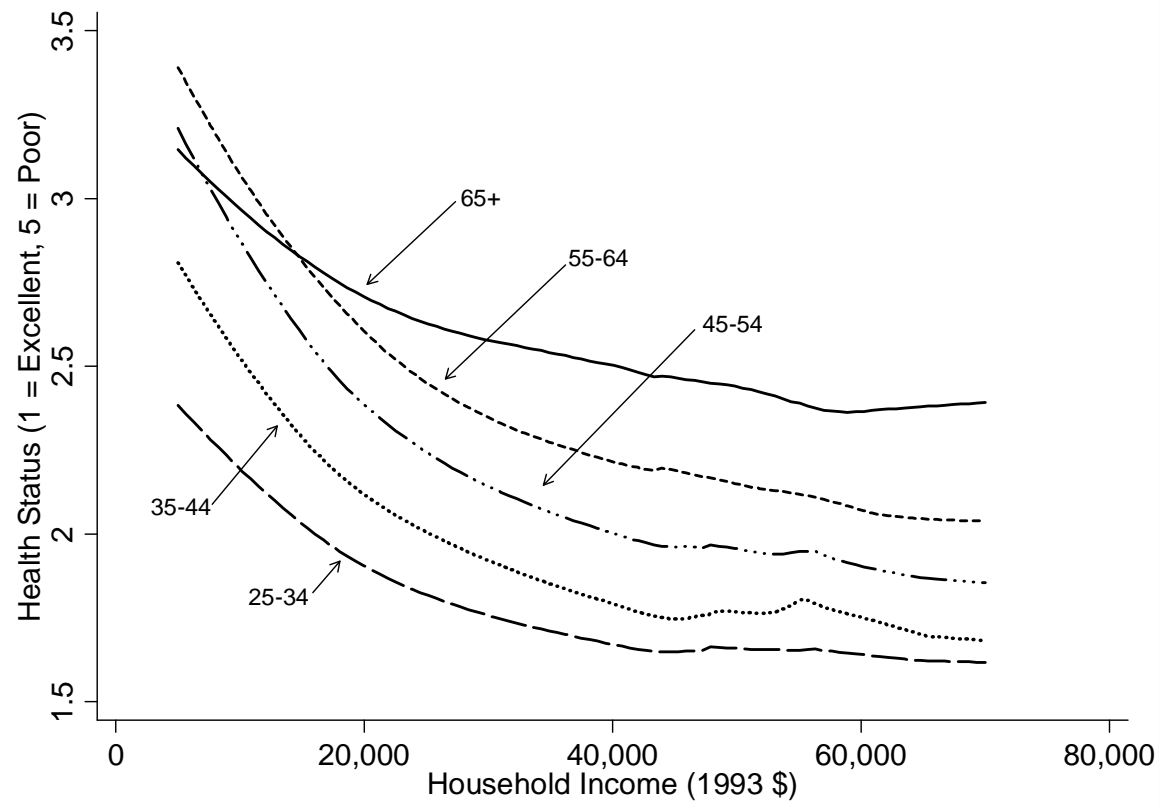

Notes: The curves are local linear regression estimates. The regressions are weighted using the survey weights provided by the NHIS. Household income is reported in income brackets in the NHIS; it is imputed here from the March CPS of the same year as the mean income in the income bracket and education cell of the household head. 
Figure 4: Occupation and Mortality, U.S. Adults Ages 25-65, NHIS 1986-1995

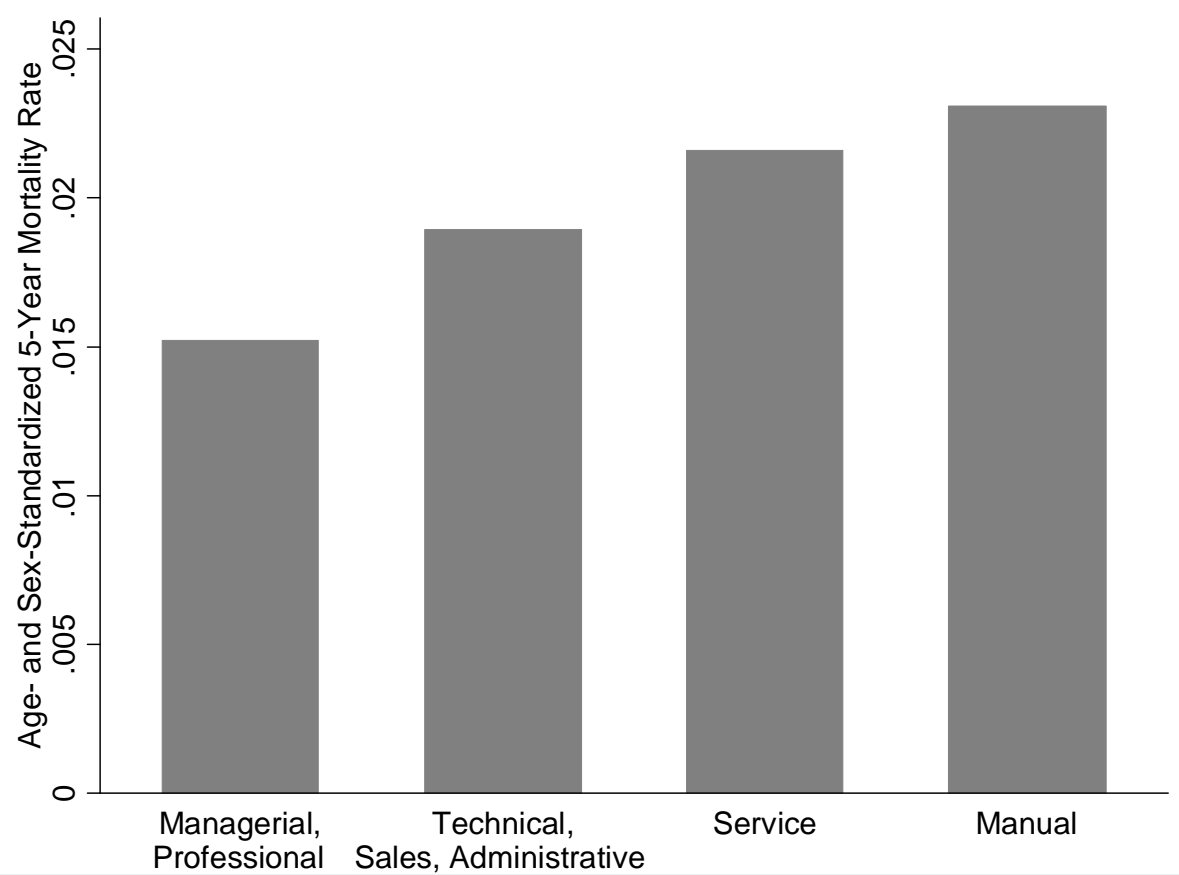

Notes: The mortality rates are age- and sex- standardized using the 2000 population structure of the United States. See text for a description of the occupations in each category. 
Figure 5a: Race and Mortality, U.S. Adults over 25, NHIS 1986-1995

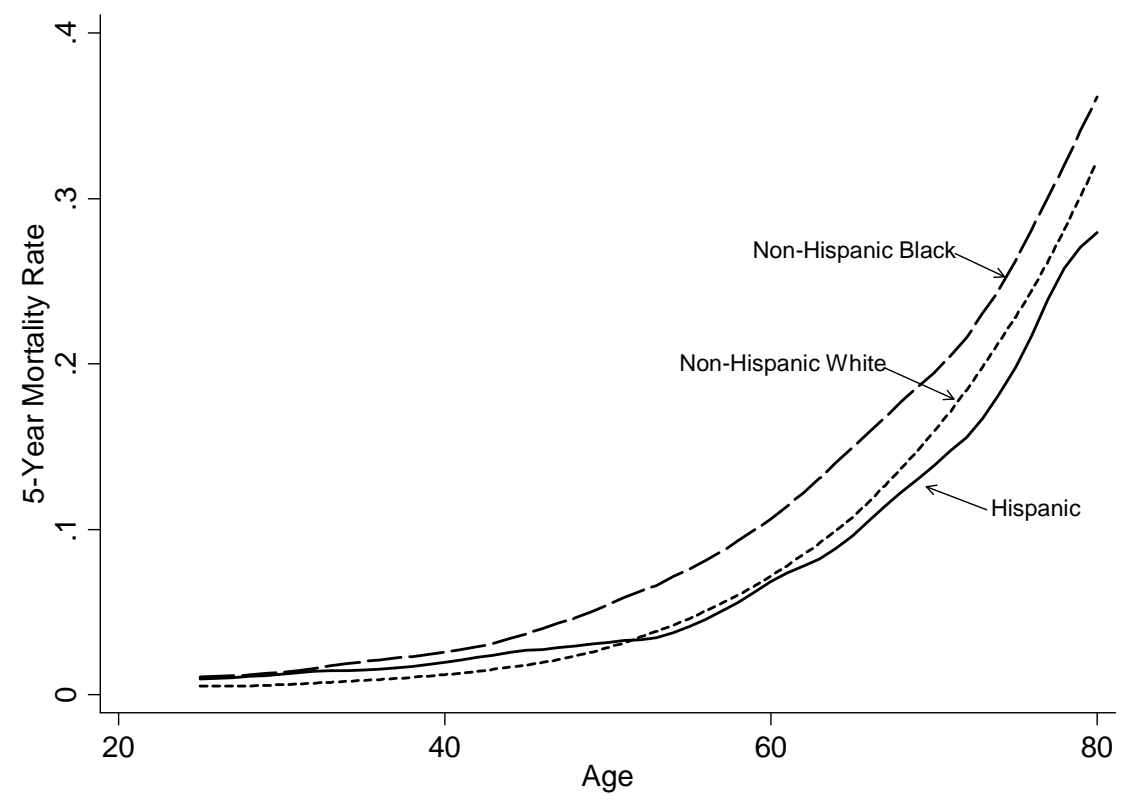

Notes: The curves are local logistic regression estimates. The regressions are weighted using the survey weights provided by the NHIS.

Figure 5b: Race and Self-Reported Health, U.S. Adults over 25, NHIS 1986-1995

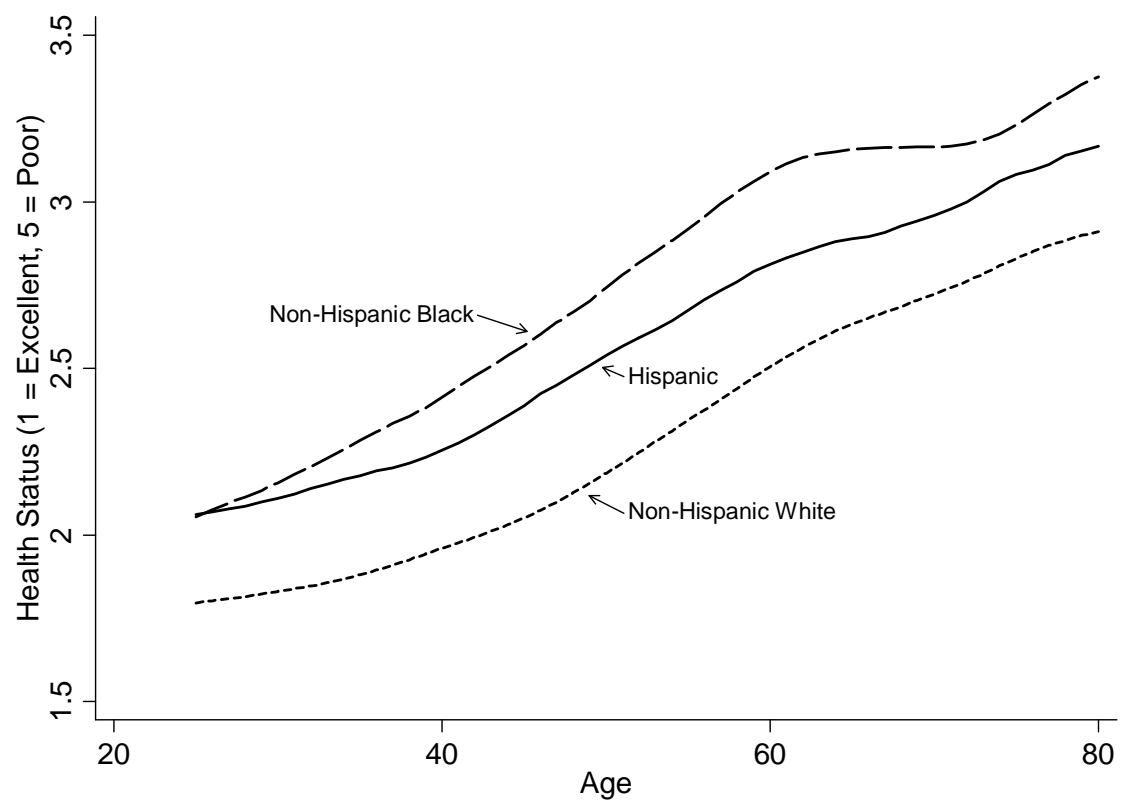

Notes: The curves are local linear regression estimates. The regressions are weighted using the survey weights provided by the NHIS. 
Table 1: Socioeconomic Status and Health, NHIS 1990, Ages 25-64

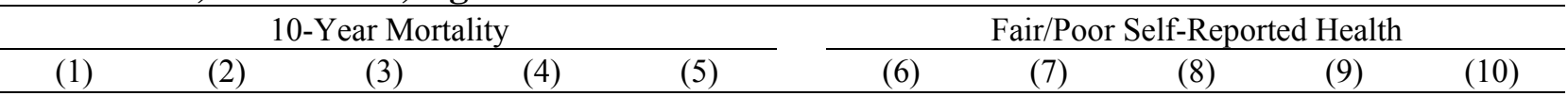

Education

Years of Education

$\begin{array}{cccccccccc}-0.33 & -0.18 & -0.11 & -0.17 & -0.18 & -1.45 & -0.82 & -0.66 & -0.82 & -0.77 \\ {[0.03]^{* *}} & {[0.04]^{* *}} & {[0.04]^{* *}} & {[0.04]^{* *}} & {[0.04]^{* *}} & {[0.06]^{* *}} & {[0.06]^{* *}} & {[0.05]^{* *}} & {[0.06]^{* *}} & {[0.05]^{* *}}\end{array}$

Household Income $($ Ref. $<\$ 15,000)$

\begin{tabular}{|c|c|c|c|c|c|c|c|c|c|c|}
\hline$\$ 15,000-\$ 24,999$ & $\begin{array}{c}-0.95 \\
{[0.27]^{* *}}\end{array}$ & $\begin{array}{l}-0.48 \\
{[0.26]}\end{array}$ & $\begin{array}{l}-0.31 \\
{[0.25]}\end{array}$ & $\begin{array}{l}-0.46 \\
{[0.27]}\end{array}$ & $\begin{array}{l}-0.45 \\
{[0.26]}\end{array}$ & $\begin{array}{c}-2.58 \\
{[0.40]^{* *}}\end{array}$ & $\begin{array}{c}-1.31 \\
{[0.36]^{* *}}\end{array}$ & $\begin{array}{c}-1.1 \\
{[0.34]^{* *}}\end{array}$ & $\begin{array}{c}-1.31 \\
{[0.36]^{* *}}\end{array}$ & $\begin{array}{c}-1.04 \\
{[0.33]^{* *}}\end{array}$ \\
\hline $5,000-\$ 49,999$ & $\begin{array}{c}-2.17 \\
{[0.25]^{* *}}\end{array}$ & $\begin{array}{c}-1.25 \\
{[0.26]^{* *}}\end{array}$ & $\begin{array}{c}-0.89 \\
{[0.24]^{* *}}\end{array}$ & $\begin{array}{c}-1.22 \\
{[0.26]^{* *}}\end{array}$ & $\begin{array}{c}-1.21 \\
{[0.26]^{* *}}\end{array}$ & $\begin{array}{c}-7.18 \\
{[0.39]^{* *}}\end{array}$ & $\begin{array}{c}-3.82 \\
{[0.37]^{* *}}\end{array}$ & $\begin{array}{c}-3.2 \\
{[0.35]^{* *}}\end{array}$ & $\begin{array}{c}-3.82 \\
{[0.37]^{* *}}\end{array}$ & $\begin{array}{c}-3.32 \\
{[0.34]^{* *}}\end{array}$ \\
\hline$\$ 50,000$ & $\begin{array}{c}-2.96 \\
{[0.32]^{* *}}\end{array}$ & $\begin{array}{c}-1.66 \\
{[0.33]^{* *}}\end{array}$ & $\begin{array}{c}-1.17 \\
{[0.31]^{* *}}\end{array}$ & $\begin{array}{c}-1.64 \\
{[0.33]^{* *}}\end{array}$ & $\begin{array}{c}-1.63 \\
{[0.33]^{* *}}\end{array}$ & $\begin{array}{c}-11.94 \\
{[0.54]^{* *}}\end{array}$ & $\begin{array}{c}-6.15 \\
{[0.54]^{* *}}\end{array}$ & $\begin{array}{c}-5.2 \\
{[0.52]^{* *}}\end{array}$ & $\begin{array}{c}-6.15 \\
{[0.53]^{* *}}\end{array}$ & $\begin{array}{c}-5.56 \\
{[0.50]^{* *}}\end{array}$ \\
\hline
\end{tabular}

Occupation (Ref. Managerial \& Professional)

$\begin{array}{lcccccccccc}\text { Tech., Sales, Admin. Support } & -0.01 & -0.53 & -0.65 & -0.54 & -0.49 & 3.02 & 0.67 & 0.5 & 0.67 & 0.86 \\ & {[0.35]} & {[0.35]} & {[0.33]^{*}} & {[0.35]} & {[0.35]} & {[0.63]^{* *}} & {[0.57]} & {[0.54]} & {[0.57]} & {[0.53]} \\ \text { Service } & 0.77 & -0.29 & -0.51 & -0.32 & -0.22 & 6.16 & 1.36 & 0.93 & 1.36 & 1.71 \\ & {[0.32]^{* *}} & {[0.34]} & {[0.31]} & {[0.34]} & {[0.33]} & {[0.56]^{* *}} & {[0.55]^{*}} & {[0.51]} & {[0.55]^{*}} & {[0.50]^{* *}} \\ \text { Operators, Fabricators, Laborers } & 1.18 & 0.02 & -0.38 & -0.02 & -0.10 & 6.82 & 1.6 & 0.99 & 1.6 & 2.01 \\ & {[0.38]^{* *}} & {[0.40]} & {[0.37]} & {[0.40]} & {[0.20]} & {[0.64]^{* *}} & {[0.62]^{*}} & {[0.58]} & {[0.62]^{*}} & {[0.58]^{* *}} \\ \text { Out of labor force } & 3.26 & 2.01 & 1.55 & 2.00 & 2.03 & 12.93 & 7.29 & 6.5 & 7.29 & 7.11 \\ & {[0.31]^{* *}} & {[0.32]^{* *}} & {[0.29]^{* *}} & {[0.32]^{* *}} & {[0.31]^{* *}} & {[0.52]^{* *}} & {[0.52]^{* *}} & {[0.49]^{* *}} & {[0.52]^{* *}} & {[0.48]^{* *}}\end{array}$


(2)

(3)

(4)

(5)

(6)

(7)

(8)

(9)

(10)

Race/ethnicity (Ref. Non-Hispanic White)

Non-Hispanic Black

Hispanic

Controls for:

Demographic Variables

Other SES Variables

Behavioral Variables

Knowledge Variables

Stress Variables

1.47

$[0.29]^{* *}$

0.67

$[0.29]^{*}$

0.88

$-0.06$

$[0.42]^{*}$

[0.42]

0.95
$[0.27]^{*}$

[0.27]**

0.40

[0.39]

0.66

$[0.29]^{* *}$

0.71

$-0.06$

[0.29]*

[0.41]

$-0.01$

[0.41]

$\begin{array}{cc}5.5 & 2.28 \\ {[0.47]^{* *}} & {[0.39]^{* *}} \\ 4.29 & -0.58 \\ {[0.64]^{* *}} & {[0.57]}\end{array}$

2.34

2.28

2.53

[0.57]

0.08

$[0.40]^{*}$

$[0.37]^{* *}$

[0.53] [0.57]

0.06

[0.52]

Observations

X

$\begin{array}{ll}X & X \\ X & X \\ & X\end{array}$

X

$\mathrm{X}$

$\mathrm{X}$

X

$\mathrm{X}$

$\mathrm{X}$

$$
\mathrm{X}
$$

$\begin{array}{ccccc}X & X & X & X & X \\ X & X & X & X \\ & X & & \\ & & X & X\end{array}$

$$
\begin{aligned}
& X \\
& X \\
& X
\end{aligned}
$$

\begin{abstract}
Notes: The estimates represent marginal effects from logit estimations, evaluated at the means of the independent variables. All estimates are multiplied by 100 , in order to reflect marginal effects in percentage points. Brackets contain robust standard errors. $* \mathrm{p}<0.05, * * \mathrm{p}<0.01$. Mean 10 -year mortality is $5.59 \%$, and mean fair/poor health is $9.22 \%$. Demographic variables include age, sex, region, size of metropolitan area, marital status, and family size. Behavioral variables include current smoker, ever smoker, number of cigarettes per day, obesity, regular exercise, and use of a seat-belt always.

Knowledge variables include the number of correct responses to health questions about smoking, drinking, and heart disease, with one tally for each of these three domains. Stress variables include self-reports of "a lot of stress" over the past week and over the past year. The race specifications also include a dummy for "other" race.
\end{abstract}

